\title{
A collaborative emergency decision making approach based on BWM and TODIM under interval 2-tuple linguistic environment
}

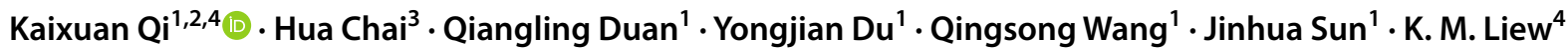

Received: 28 January 2021 / Accepted: 10 August 2021 / Published online: 19 September 2021

○ The Author(s), under exclusive licence to Springer-Verlag GmbH Germany, part of Springer Nature 2021

\begin{abstract}
Emergencies require various emergency departments to collaborate to achieve timely and effective emergency responses. Thus, the overall performance of emergency response is influenced not only by the efficiency of each department alternative but also by the coordination effect among different department alternatives. This paper proposes a collaborative emergency decision making (CEDM) approach considering the synergy among different department alternatives based on the best-worst method (BWM) and TODIM (an acronym in Portuguese of interactive and multiple attribute decision making) method within an interval 2-tuple linguistic environment. First, the evaluation information provided by decision makers (DMs) is represented by interval 2-tuple linguistic variables to reflect and model the underlying diversity and uncertainty. On the basis of the DMs' evaluations, the individual and collaborative performance evaluations of multi-alternative combinations composed of different department alternatives are constructed. Then, the BWM is extended into interval 2-tuple linguistic environment to obtain the weights of evaluation criteria, where the group decision making is taken into account in an interval fuzzy mathematical programming model. Furthermore, to derive more practical and accurate decision results, an interval 2-tuple linguistic TODIM (ITL-TODIM) method is proposed by considering the DMs' psychological behaviours. In the developed ITL-TODIM method, both the gain and loss degrees of one alternative relative to another are simultaneously computed. Finally, a numerical example is presented to illustrate the applicability of the proposed method. Sensitivity and comparative analyses are also provided to demonstrate the effectiveness and advantages of the proposed approach.
\end{abstract}

Keywords Emergency decision making $\cdot$ Interval 2-tuple linguistic $\cdot$ Multiple criteria decision making $\cdot$ Best-worst method $(\mathrm{BWM}) \cdot \mathrm{TODIM}$

\section{Introduction}

In the past few years, different kinds of emergency events have frequently occurred around the world, such as the tsunami in the Indian Ocean in 2004, Hurricane Katrina in the

Qingsong Wang

pinew@ustc.edu.cn

Jinhua Sun

sunjh@ustc.edu.cn

Kaixuan Qi

qkx@mail.ustc.edu.cn

Hua Chai

xc30@mail.ustc.edu.cn

Qiangling Duan

duanql@ustc.edu.cn

Yongjian Du

luyjabc@outlook.com
United States in 2005, the 9.0 magnitude earthquake in Japan in 2011, the Tianjin Port explosion in China in 2015, the novel coronavirus pneumonia that first broke out in China in 2019 and the Beirut Port explosion in Lebanon in 2020. These emergencies not only brought great inconvenience to

\section{K. M. Liew}

kmliew@cityu.edu.hk

1 State Key Laboratory of Fire Science, University of Science and Technology of China, Hefei 230026, China

2 Safety and Emergency Technology Research Center, China Waterborne Transport Research Institute, Beijing 100088, China

3 Emergency Management Training Center, Party School of the Central Committee of C.P.C (National Academy of Governance), Beijing 100091, China

4 Department of Architecture and Civil Engineering, City University of Hong Kong, Tat Chee Avenue, Kowloon, Hong Kong, China 
human life and work but also caused much loss of life and property. After an emergency, to reduce or eliminate various losses and potential hazards, effective emergency solutions must be developed within a short period of time $[46,66]$. However, because of the lack of decision information and the uncertainty and complexity of emergencies, it is difficult to cope with emergencies through conventional response measures [71]. Consequently, the emergency decision making (EDM) problem has recently attracted increasing attention from scholars and governments $[2,9,13,22,25,61$, 65]. Multiple criteria decision making (MCDM) techniques, which support decision makers (DMs) in choosing the best option from several alternatives based on multiple and often conflicting criteria, are considered effective means to determine the best solution in EDM problems [4, 8, 36, 52].

In the literature, many studies have addressed EDM problems within the framework of MCDM [7, 26, 45, 55, $62,70]$. Previous works on solving EDM problems mainly concentrated on selecting the best emergency response alternative from several ones based on multiple criteria, and rarely considered the synergy among alternatives supplied by different emergency departments. However, because of the complexity and urgency of emergencies and the interdependence of social systems, an emergency response system is undoubtedly a complex whole composed of multiple elements. To respond to emergencies in a timely and effective manner, it is necessary to integrate the emergency response forces of multiple departments to carry out an emergency rescue [6]. Thus, emergency responses usually involve many emergency decision making departments, and each department has its own alternatives in response to an emergency. In these circumstances, a desirable emergency solution should be the organic combination of multiple department emergency alternatives. From this realistic point of view, for emergency management, the overall performance of emergency response is influenced not only by the efficiency of each department alternative (individual performance) but also by the coordination effect between different department alternatives (collaborative performance). Therefore, for the generation of a reasonable and effective emergency solution, collaborative emergency decision making (CDEM) should be conducted by taking multiple department emergency alternatives and their synergy into consideration. Accordingly, it is meaningful and significant to develop a CDEM approach to handle this issue.

Based on the concept of fuzzy sets, many researchers have solved EDM problems [9, 36, 46, 55]. However, in real EDM processes, due to the uncertainty of emergency situations and the inaccuracy of decision information, it is difficult for DMs to express their evaluations with fuzzy values [37, 47]. Instead, the use of linguistic variables, first proposed by Zadeh [68], has been regarded as an effective way to depict the fuzziness and uncertainty of DMs' assessments.
The interval 2-tuple linguistic representation model proposed by Zhang [69] allows DMs to express their evaluation information between two linguistic terms in the form of an interval 2-tuple from predefined linguistic term sets, which may have different granularities. Additionally, this model, as an extension of the 2-tuple linguistic representation model, is renowned for its ability to exactly process linguistic information and avoid information distortion or loss $[42,53]$. Therefore, a method based on the interval 2-tuple linguistic representation model not only is highly useful in reflecting the diversity and uncertainty of DMs' linguistic assessments but also can be used as a highly flexible and accurate tool in various fuzzy and uncertain linguistic information environments $[5,48]$. Since its introduction, this model has received much attention and has been successfully applied in many fields [12, 21, 23, 24, 38, 29]. Hence, the interval 2-tuple linguistic representation model is of great value in dealing with the diversity, fuzziness and uncertainty of the emergency decision information provided by DMs in CEDM.

The determination of criteria weights is a critical part of MCDM problems [16, 50]. The best-worst method (BWM), recently developed by Rezaei [50], is an innovative and simple method for the determination of criteria weights and is considered an appropriate alternative to using the analytic hierarchy process (AHP) method [67]. Compared with the AHP method, the BWM is flexible and efficient, and has two pivotal superiorities [64]: (1) the BWM constructs comparison relations that require fewer comparisons than the pairwise comparison matrix in the AHP, and (2) the criteria weights obtained by the BWM are more consistent with practical cases. Hence, the BWM can be regarded as a convenient and robust way to obtain the weights of criteria in EDM problems. This method has been extended with many fuzzy theories and widely utilized in real-world MCDM problems $[15,16,28,39,41,63]$. A detailed literature review on the extension and application of the BWM can be found in Mi et al. [43] and Yazdi et al. [67]. To date, however, there have been no relevant extensions of the BWM into interval 2-tuple linguistic environment, nor has there been research on their applications to cope with EDM problems. Furthermore, on account of the complexity of emergency situations and the participation of multiple departments, taking multiple opinions of DMs from different departments is worth advocating in EDM. Therefore, it is expected to integrate the BWM with interval 2-tuple linguistic representation model to address CEDM issues while simultaneously considering group decision making.

Different approaches have been adopted to rank the EDM solutions, such as Technique in Order of Preference by Similarity to Ideal Solution (TOPSIS) [2], VIseKriterijumska Optimizacija I Kompromisno Resenje (VIKOR) [60], Weighted Distance Based Approximation (WDBA) and COmbinative Distance-based ASsessment (CODAS) 
[46], DEcision-MAking Trial and Evaluation Laboratory (DEMATEL) [4], QUALItative FLEXible multiple criteria (QUALIFLEX) [11] and Preference Ranking Organization METHod for Enrichment Evaluations II (PROMETHEE II) [45]. Although these methods are beneficial to EDM, they assume that DMs are completely rational. Many behavioural experiments have shown that DMs have bounded cognition in decision making processes under risk and uncertainty [3, $19,58]$. DMs usually have psychological expectations and are more sensitive to losses than to gains [1]. Because of the irregularity in emergencies, practical EDM processes are characterized by risks and uncertainties [10]. Thus, DMs' psychological behaviours are crucial and must be considered in solving EDM problems. As a typical MCDM approach that considers the psychological behaviours of DMs, the TODIM (an acronym in Portuguese of interactive and multiple attribute decision making) method proposed by Gomes and Lima [14] has gained much attention from researchers. Different from the studies using prospect theory to describe DMs' psychological behaviours $[8,36$, 70], the TODIM method does not require the aspiration levels of criteria, which are usually difficult to determine in advance. At present, the TODIM method has been extended into various types of fuzzy environments [24, 33-40, 49, 57]. However, little attention has been given to the extension of TODIM method into the interval 2-tuple linguistic context. In view of the advantages of interval 2-tuple linguistic representation model discussed before, it is encouraged to extend the TODIM method into interval 2-tuple linguistic environment to generate more reasonable decision results in CEDM.

Based on the above motivations, the objective of this paper is to develop an integrated approach combining the interval 2-tuple linguistic BWM (ITL-BWM) method and interval 2-tuple linguistic TODIM (ITL-TODIM) method to solve CEDM problems that consider the synergy among different department alternatives. The main contributions of this study are summarized as follows:

(1) In the EDM process, the synergy among different department alternatives is taken into account, and the construction processes of the individual performance evaluations and collaborative performance evaluations of multi-alternative combinations comprising different department alternatives are suggested.

(2) A new extension of the BWM with interval 2-tuple linguistic information is proposed to determine the criteria weights. Group decision making is incorporated into an interval fuzzy mathematical programming model in the developed ITL-BWM.

(3) The TODIM method is extended into interval 2-tuple linguistic environment by considering DMs' psychological behaviours, in which the gain degree and loss degree of one alternative relative to another are both calculated to derive more accurate decision results.

The remainder of this paper is organized as follows. Section 2 reviews the current EDM methods. Section 3 introduces some basic concepts of the interval 2-tuple linguistic information. Section 4 describes the proposed CEDM methodology in detail. In Sect. 5, a numerical example is presented. Next, sensitivity and comparative analyses are conducted in Sect. 6. Finally, some concluding remarks are given in Sect. 7.

\section{Literature review}

Currently, a variety of methods have been developed for EDM under diverse uncertain circumstances to effectively respond to and resolve emergency events. For example, Ju and Wang [18] proposed a method of combining Dempster-Shafer evidence theory with the analytic hierarchy process (DS/AHP) and extended TOPSIS for emergency alternative evaluation and selection. Gao et al. [13] proposed an emergency decision support method using probabilistic linguistic preference relations and case-based reasoning. Ding and Liu [7] presented an extended zero-sum game approach based on the BWM and Pythagorean fuzzy uncertain linguistic variables for solving EDM problems. The probabilistic linguistic weighted averaging operator combining Dempster-Shafer evidence theory was advanced by $\mathrm{Li}$ and Wei [22] for the EDM of a serious mine accident. Ding et al. [11] suggested a large group EDM method by extending the QUALIFLEX method using linguistic Z-numbers. Ashraf and Abdullah [2] designed three EDM algorithms using TOPSIS, grey relational analysis and Einstein aggregation operators under a spherical fuzzy environment. To manage emergency alternative selection under group DMs, a method based on entropy weight and intuitionistic fuzzy DEMATEL was developed by Chen et al. [4]. Liang et al. [25] combined the linguistic distribution weighted power average operator and linguistic distribution multi-attributive border approximation area comparison method to solve the emergency alternative selection problem. Aiming at describing DMs' psychological characteristics in emergency events, Liu et al. [36] extended the trapezoidal intuitionistic fuzzy thermodynamic method with prospect theory to appraise emergency alternatives. According to the constructed prospect decision matrix, an extended VIKOR approach was suggested by Ding and Liu [8] to address EDM problems with 2 -dimensional uncertain linguistic information. For a mine EDM problem, Liang et al. [26] proposed a multi-granularity proportional hesitant fuzzy linguistic TODIM method. Wang et al. [61] suggested a regret theory-based EDM model for the emergency response to different rainstorm disaster 
scenarios. Thereafter, Wang and Day [62] applied the AHP method to explore the selection and prioritization of major decision making factors for typhoon disaster preparedness and emergency response. Ding et al. [9] integrated the TODIM method with bidirectional projection to solve the group EDM problem in the context of hesitant triangular fuzzy sets. Based on case-based reasoning and the cloud model, Xia et al. [65] constructed an EDM method to handle the risk decision making problem in emergency response alternative selection. Rong et al. [52] propounded a decision methodology that combines the novel score function and generalized picture fuzzy Archimedean copula prioritized aggregation operators to determine the issue of emergency management scheme evaluation. In addition, Zhou et al. [72] provided an overview of the EDM methods for natural disasters and presented a detailed illustration of the construction and development of emergency decision support systems.

The above literature review shows that various methods have been introduced to cope with EDM problems in vague and indeterminate environments. However, the extant works rarely consider multiple department emergency alternatives and their synergy in EDM processes. Moreover, little attention has been paid to EDM problems in the context of interval 2-tuple linguistic information. In addition, to the best of our knowledge, an investigation of the BWM and TODIM with interval 2-tuple linguistic information to address emergencies cannot be found in the existing literature. Therefore, to bridge these research gaps, this paper proposes a collaborative emergency decision making approach combining the BWM and TODIM within the interval 2-tuple linguistic information environment to solve EDM problems. The developed EDM method can not only manage the evaluation information of DMs flexibly and accurately but also support the rescue team in finding the optimal emergency solution to an emergency event reasonably and effectively.

\section{Preliminaries}

This section introduces some basic concepts of interval 2-tuple linguistic information.

\subsection{2-Tuple linguistic information}

Let $\mathrm{S}=\left\{\mathrm{s}_{0}, s_{1}, \ldots, s_{g}\right\}$ be a predefined linguistic term set with granularity $\mathrm{g}+1$, where $s_{\mathrm{i}}$ obeys the following rule: if $\mathrm{m}>n$, then $\mathrm{s}_{\mathrm{m}}>s_{n}$. The 2-tuple fuzzy linguistic representation model, developed by Herrera and Martínez [17], expresses linguistic information using a linguistic 2-tuple $\left(s_{i}, \alpha\right)$, where $s_{i}$ is a linguistic term from $\mathrm{S}$ and $\alpha$ denotes the value of symbolic translation. Together with the 2-tuple $\left(s_{i}, \alpha\right)$, there exists a numerical value $\beta$ representing the aggregation result of the linguistic symbol. In the classical 2-tuple linguistic model [17], $\beta$ ranges from 0 to $g$. Consequently, there is a limitation that the range of $\beta$ varies with the granularity of the linguistic term sets. To overcome this limitation, Chen and Tai [56] proposed a generalized 2-tuple linguistic model.

Definition 1 [56]. Let $\mathrm{S}=\left\{\mathrm{s}_{0}, s_{1}, \ldots, s_{g}\right\}$ be a linguistic term set and $\beta \in[0,1]$ be a value expressing the result of a symbolic aggregation operation. To obtain the 2-tuple equivalent to $\beta$, the following generalized translation function is defined:

$\Delta:[0,1] \rightarrow S \times[-0.5 / g, 0.5 / g)$,

$\Delta(\beta)=\left(s_{i}, \alpha\right)$ with $\left\{\begin{array}{l}s_{i}, \quad \mathrm{i}=\operatorname{round}(\beta \cdot g), \\ \alpha=\beta-i / g, \alpha \in[-0.5 / g, 0.5 / g),\end{array}\right.$

where round $(\cdot)$ is the usual rounding operation, $s_{i}$ possesses the closest index label to $\beta$ and $\alpha$ is the symbolic translation value.

Definition 2 [56]. Let $\mathrm{S}=\left\{\mathrm{s}_{0}, s_{1}, \cdots, s_{g}\right\}$ be a linguistic term set and $\left(s_{i}, \alpha\right)$ be a 2 -tuple. There is a reverse function $\Delta^{-1}$ to transform a 2 -tuple into its equivalent numerical value $\beta \in[0,1]$, where:

$\Delta^{-1}: S \times[-0.5 / g, 0.5 / g) \rightarrow[0,1]$,

$\Delta^{-1}\left(s_{i}, \alpha\right)=i / g+\alpha=\beta$.

Obviously, a linguistic term $s_{i}$ can be converted into a 2-tuple $\left(s_{i}, 0\right)$.

Theorem 1 [17]. Let $\left(s_{\mathrm{k}}, \alpha_{1}\right)$ and $\left(s_{l}, \alpha_{2}\right)$ be two 2-tuples, the comparison of which can be performed according to an ordinary lexicographic order as follows:

(1) If $k<$ l, then $\left(\mathrm{s}_{\mathrm{k}}, \alpha_{1}\right)<\left(\mathrm{s}_{\mathrm{l}}, \alpha_{2}\right)$;

(2) If $k=l$, then

(a) if $\alpha_{1}=\alpha_{2}$, then $\left(\mathrm{s}_{\mathrm{k}}, \alpha_{1}\right)=\left(\mathrm{s}_{1}, \alpha_{2}\right)$;

(b) if $\alpha_{1}<\alpha_{2}$, then $\left(\mathrm{s}_{\mathrm{k}}, \alpha_{1}\right)<\left(\mathrm{s}_{1}, \alpha_{2}\right)$;

(c) if $\alpha_{1}>\alpha_{2}$, then $\left(\mathrm{s}_{\mathrm{k}}, \alpha_{1}\right)>\left(\mathrm{s}_{1}, \alpha_{2}\right)$.

\subsection{Interval 2-tuple linguistic information}

Based on the 2-tuple linguistic model [56], Zhang [69] put forward a novel interval 2-tuple linguistic representation model, which has more advantages in addressing vague and incomplete linguistic information.

Definition 3 [69]. Let $\mathrm{S}=\left\{\mathrm{s}_{0}, s_{1}, \cdots, s_{g}\right\}$ be a linguistic term set. An interval 2-tuple is composed of two 2-tuples, denoted as $\left[\left(s_{\mathrm{i}}, \alpha_{1}\right),\left(s_{j}, \alpha_{2}\right)\right]$, where $i \leq j$ and $\alpha_{1} \leq \alpha_{2}$ if $i=j$, 
$s_{\mathrm{i}}\left(s_{\mathrm{j}}\right)$ and $\alpha_{1}\left(\alpha_{2}\right)$ represent the linguistic term from $\mathrm{S}$ and the symbolic translation value, respectively. The following function is defined to acquire the interval 2-tuple equivalent to an interval value $\left[\beta_{1}, \beta_{2}\right]\left(\beta_{1}, \beta_{2} \in[0,1], \beta_{1} \leq \beta_{2}\right)$ :

$\Delta\left(\left[\beta_{1}, \beta_{2}\right]\right)=\left[\left(s_{i}, \alpha_{1}\right),\left(s_{j}, \alpha_{2}\right)\right]$, with $\left\{\begin{array}{l}s_{i}, i=\operatorname{round}\left(\beta_{1} \cdot g\right), \\ s_{j}, j=\operatorname{round}\left(\beta_{2} \cdot g\right), \\ \alpha_{1}=\beta_{1}-i / g, \alpha_{1} \in[-0.5 / g, 0.5 / g), \\ \alpha_{2}=\beta_{2}-j / g, \alpha_{2} \in[-0.5 / g, 0.5 / g) .\end{array}\right.$
Fig. 1. First, the construction processes of individual and collaborative performance evaluations of multi-alternative combinations regarding individual criteria and collaborative criteria are introduced. Second, the ITL-BWM method is developed to calculate the weights of individual criteria and
Conversely, a reverse function $\Delta^{-1}$ to transform an interval 2-tuple into its equivalent interval value $\left[\beta_{1}, \beta_{2}\right]$ always exists, where:

$\Delta^{-1}\left(\left[\left(s_{\mathrm{i}}, \alpha_{1}\right),\left(s_{j}, \alpha_{2}\right)\right]\right)=\left[i / g+\alpha_{1}, j / g+\alpha_{2}\right]=\left[\beta_{1}, \beta_{2}\right]$.

Definition 4 [30]. Let $\left[\left(r_{1}, \alpha_{1}\right),\left(t_{1}, \varepsilon_{1}\right)\right]$ and $\left[\left(r_{2}, \alpha_{2}\right),\left(t_{2}, \varepsilon_{2}\right)\right]$ be two interval 2-tuples and $\lambda \in[0,1]$, then the following basic operations can be defined:

$$
\begin{aligned}
& {\left[\left(r_{1}, \alpha_{1}\right),\left(t_{1}, \varepsilon_{1}\right)\right]+\left[\left(r_{2}, \alpha_{2}\right),\left(t_{2}, \varepsilon_{2}\right)\right]} \\
& \quad=\Delta\left[\Delta^{-1}\left(r_{1}, \alpha_{1}\right)+\Delta^{-1}\left(r_{2}, \alpha_{2}\right), \Delta^{-1}\left(t_{1}, \varepsilon_{1}\right)+\Delta^{-1}\left(t_{2}, \varepsilon_{2}\right)\right] ; \\
& \quad\left[\left(r_{1}, \alpha_{1}\right),\left(t_{1}, \varepsilon_{1}\right)\right] \times\left[\left(r_{2}, \alpha_{2}\right),\left(t_{2}, \varepsilon_{2}\right)\right] \\
& \quad=\Delta\left[\Delta^{-1}\left(r_{1}, \alpha_{1}\right) \times \Delta^{-1}\left(r_{2}, \alpha_{2}\right), \Delta^{-1}\left(t_{1}, \varepsilon_{1}\right) \times \Delta^{-1}\left(t_{2}, \varepsilon_{2}\right)\right] ; \\
& \lambda\left[\left(r_{1}, \alpha_{1}\right),\left(t_{1}, \varepsilon_{1}\right)\right]=\Delta\left[\lambda \Delta^{-1}\left(r_{1}, \alpha_{1}\right), \lambda \Delta^{-1}\left(t_{1}, \varepsilon_{1}\right)\right] ;
\end{aligned}
$$

Definition 5 [69]. Let $X=\left\{\left[\left(\mathrm{r}_{1}, \alpha_{1}\right),\left(\mathrm{t}_{1}, \varepsilon_{1}\right)\right],\left[\left(\mathrm{r}_{2}, \alpha_{2}\right)\right.\right.$, $\left.\left.\left(\mathrm{t}_{2}, \varepsilon_{2}\right)\right], \cdots,\left[\left(\mathrm{r}_{n}, \alpha_{n}\right),\left(\mathrm{t}_{n}, \varepsilon_{n}\right)\right]\right\}$ be a set of interval 2-tuples and $w=\left(w_{1}, w_{2}, \ldots, w_{n}\right)^{T}$ be their associated weighting vector, with $w_{i} \in[0,1]$ and $\sum_{i=1}^{n} w_{i}=1$. The interval 2-tuple weighted average (ITWA) operator is defined as:

$$
\begin{aligned}
& \operatorname{ITWA}\left(\left[\left(\mathrm{r}_{1}, \alpha_{1}\right),\left(\mathrm{t}_{1}, \varepsilon_{1}\right)\right],\left[\left(\mathrm{r}_{2}, \alpha_{2}\right),\left(\mathrm{t}_{2}, \varepsilon_{2}\right)\right], \ldots,\left[\left(\mathrm{r}_{n}, \alpha_{n}\right),\left(\mathrm{t}_{n}, \varepsilon_{n}\right)\right]\right) \\
& =\Delta\left[\sum_{i=1}^{n} w_{i} \Delta^{-1}\left(r_{i}, \alpha_{i}\right), \sum_{i=1}^{n} w_{i} \Delta^{-1}\left(\mathrm{t}_{i}, \varepsilon_{i}\right)\right] .
\end{aligned}
$$

\section{Proposed methodology}

In this section, an integrated method combining the BWM and TODIM is developed to solve the CEDM problems within the interval 2-tuple fuzzy linguistic environment. The basic procedure of the proposed method is shown in collaborative criteria. Third, the ITL-TODIM method is proposed to determine the priority ranking of multi-alternative combinations on the basis of individual and collaborative performances.

For a CEDM problem, let $D=\left\{D_{1}, D_{2}, \ldots, D_{J}\right\}$ be a set of emergency departments, $D M=\left\{D M_{1}, D M_{2}, \ldots, D M_{J}\right\}$ be a set of DMs from each department, $\lambda=\left\{\lambda_{1}, \lambda_{2}, \ldots, \lambda_{J}\right\}$ be the weighting vector of $D M$, with $\lambda_{j} \in[0,1]$ and $\sum_{\mathrm{j}=1}^{J} \lambda_{j}=1, A^{D_{j}}=\left\{A_{1}^{D_{j}}, A_{2}^{D_{j}}, \ldots, A_{N_{D_{j}}}^{D_{j}}\right\}$ be a set of emergency alternatives provided by $D_{j}(j=1,2, \ldots, J)$, $I C=\left\{I C_{1}, I C_{2}, \ldots, I C_{I}\right\}$ be a set of individual criteria, and $C C=\left\{C C_{1}, C C_{2}, \ldots, C C_{C}\right\}$ be a set of collaborative criteria. This study takes both the individual performances and collaborative performances of multi-alternative combinations into consideration and focuses on how to select the best response solution to an emergency event. Then, the main steps of the proposed approach integrating the ITL-BWM and ITL-TODIM are presented as shown below.

\section{Stage 1: Obtain the individual and collaborative perfor- mance evaluations}

Emergency response usually requires multiple emergency departments to carry out rescue activities. To obtain a better yield of emergency activities, not only the effectiveness of the emergency response of a single department but also the effectiveness of coordination between different departments needs to be considered. Hence, when selecting the most suitable alternative combination, both the individual performances and collaborative performances of multialternative combinations should be assessed.

(1) Individual performance evaluations

Step 1.1: Decision maker $D M_{j}(j=1,2, \ldots, J)$ chooses a linguistic term set $S^{j}$ from the multi-granularity ones and evaluates the performance of alternative $A_{n_{D_{j}}}^{D_{j}}\left(n_{D_{j}}=1,2, \ldots, N_{D_{j}}\right)$ provided by his/her department $D_{j}$ with respect to individual criterion $I C_{i}(i=1,2, \ldots, I)$ through an interval linguistic variable $\dot{e}_{n_{D_{j}}, i}^{j}=\left[r_{n_{D_{j}}, i}^{j}, t_{n_{D_{j}}, i}^{j}\right.$, with $r_{n_{D_{j}}, i}^{j}, t_{n_{D_{j}}, i}^{j} \in S^{j}$ and $r_{n_{D_{j}}, i}^{j}<t_{n_{D_{j}}, i^{*}}^{j}$ 
Fig. 1 The procedural steps of the proposed approach

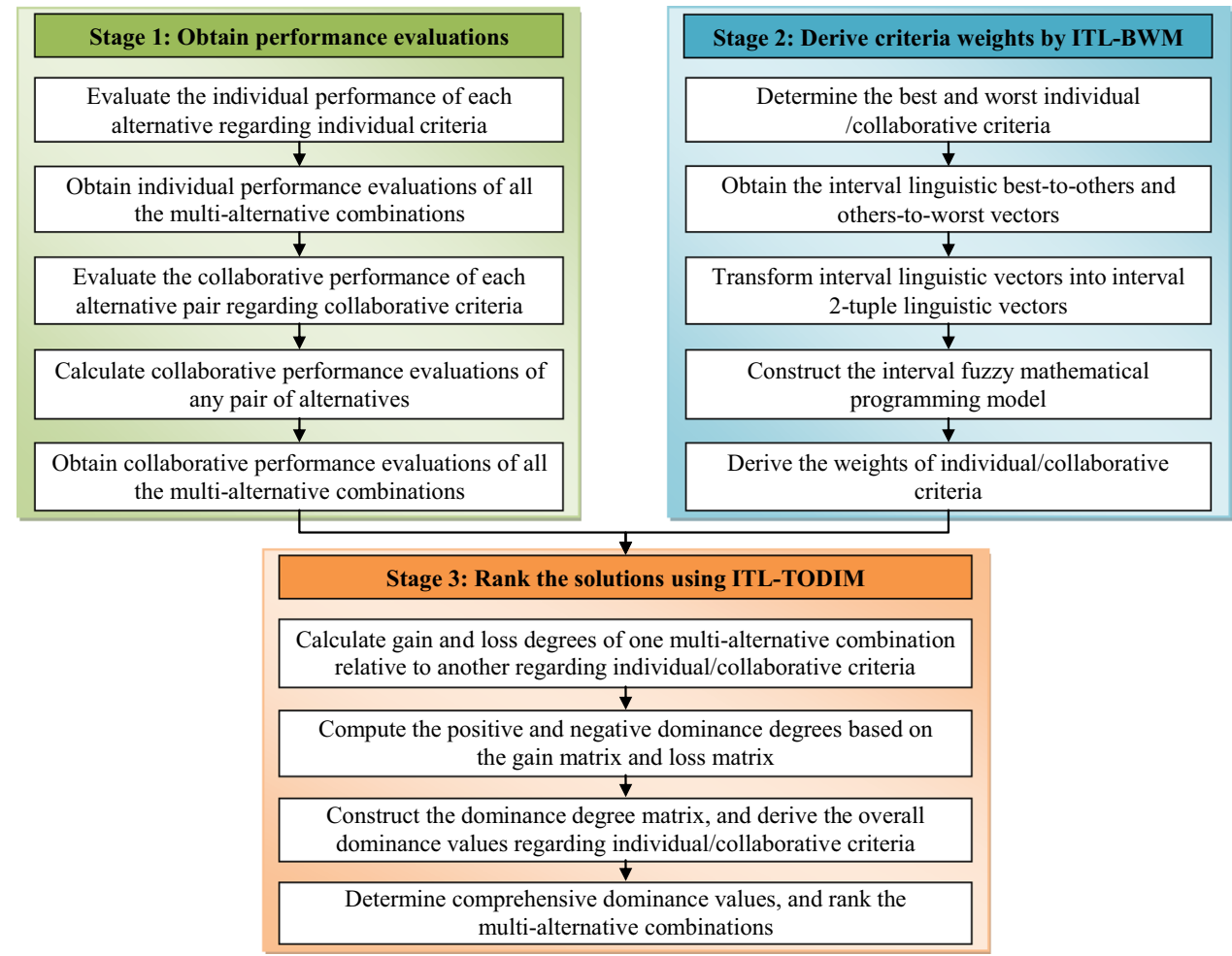

Then, transform $\dot{e}_{n_{D_{j}}, i}^{j}$ into interval 2-tuple linguistic

(2) Collaborative performance evaluations

variable $e_{n_{D_{j}, i}}^{j}=\left[\left(r_{n_{D_{j}}, i}^{j}, 0\right),\left(t_{n_{D_{j}}, i}^{j}, 0\right)\right]$.

Step 1.2: For any multi-alternative combination $A_{n_{D_{1}}}^{D_{1}} A_{n_{D_{2}}}^{D_{2}} \ldots A_{n_{D_{J}}}^{D_{J}}$, its individual performance evaluation regarding $I C_{i}$ is determined by
Step 1.3: $D M_{p}$ and $D M_{q}(p, q=1,2, \ldots, J, p<q)$ respectively provide their evaluations $\dot{e}_{n_{D_{p}}, n_{D_{q}}}^{p, c}=\left[r_{n_{D_{p}}, n_{D_{q}}}^{p, c}, t_{n_{D_{p}}, n_{D_{q}}}^{p, c}\right]$ and $\dot{e}_{n_{D_{p}}, n_{D_{q}}}^{q, c}=\left[r_{n_{D_{p}}, n_{D_{q}}, c}^{q, c} t_{n_{D_{p}}, n_{D_{q}}}^{q, c}\right]$ about the performance of the pair of alternatives $\left(A_{n_{D_{p}}}^{D_{p}}, A_{n_{D_{q}}}^{D_{q}}\right)\left(n_{D_{p}}=1,2, \ldots, N_{D_{p}}, n_{D_{q}}=1,2, \ldots, N_{D_{q}}, p<q\right)$

$E_{i}^{A_{n_{1}}^{D_{1}}} A_{n_{D_{2}}}^{D_{2}} \cdots A_{n_{D_{J}}}^{D_{J}}=\sum_{j=1}^{J} \lambda_{j} \cdot e_{n_{D_{j}}, i}^{j}, i=1,2, \ldots, I, n_{D_{j}}=1,2, \ldots, N_{D_{j}}, j=1,2, \ldots, J$.

From this, the individual performance evaluations of all the multi-alternative combinations can be obtained as with respect to collaborative criterion $C C_{c}(c=1,2, \ldots, C)$. Therein, the alternatives $A_{n_{D_{p}}}^{D_{p}}$ and

$$
\begin{aligned}
& \begin{array}{lllll}
I C_{1} & \cdots & I C_{i} & \cdots & I C_{I} .
\end{array}
\end{aligned}
$$

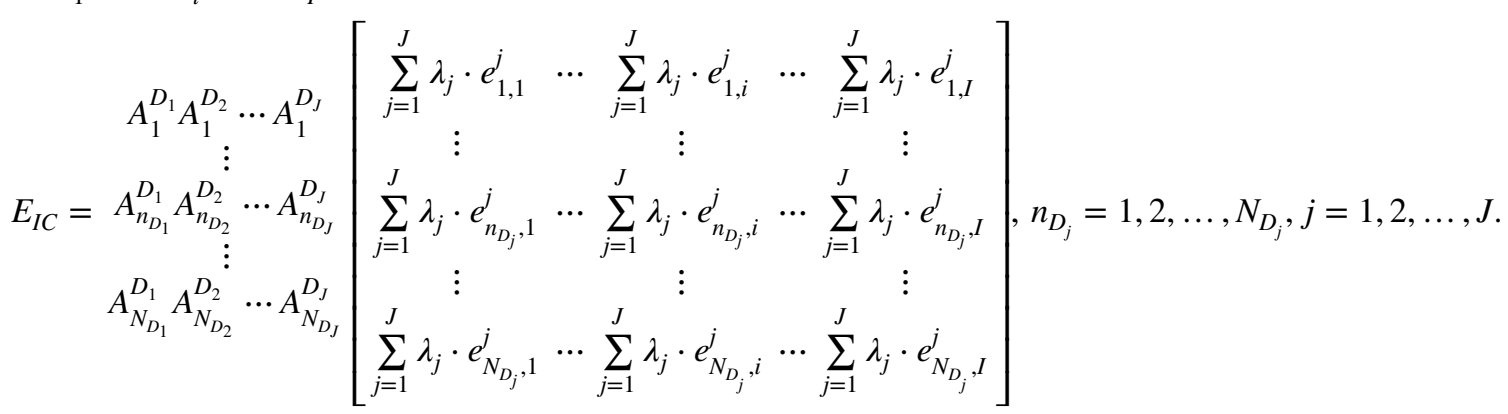

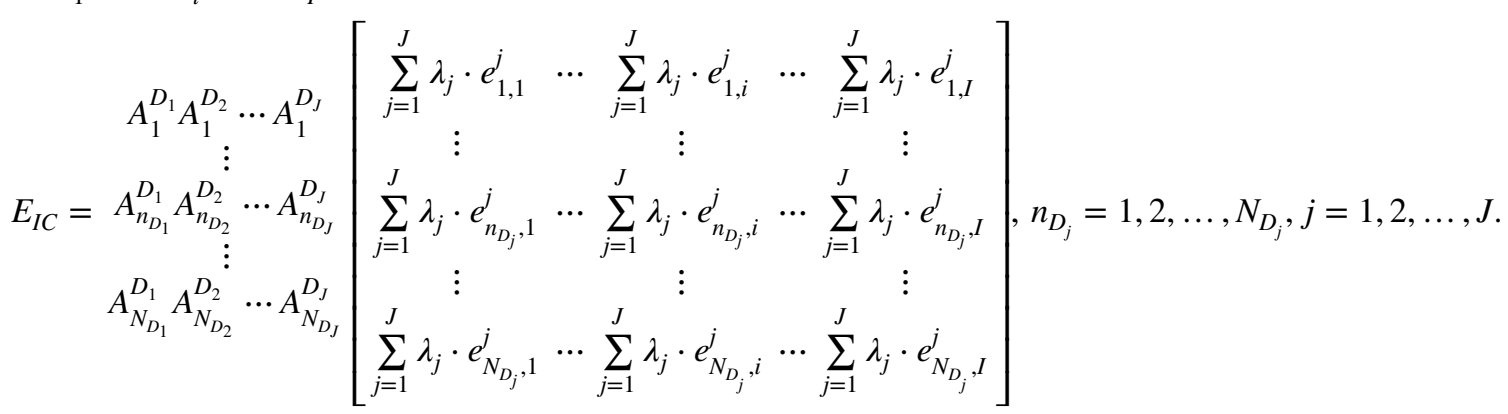


$A_{n_{D_{q}}}^{D_{q}}$ are respectively supplied by departments $D_{p}$ and $D_{q}$, and $\dot{e}_{n_{D_{p}}, n_{D_{q}}}^{p, c}$ and $\dot{e}_{n_{D_{p}}, n_{D_{q}}}^{q, c}$ are interval linguistic variables, with $r_{n_{D_{p}}, n_{D_{q}}}^{p, c}, t_{n_{D_{p}}, n_{D_{q}}}^{p, c} \in S^{p}, r_{n_{D_{p}}, n_{D_{q}}}^{q, c}, t_{n_{D_{p}}, n_{D_{q}}}^{q, c} \in S^{q}$, $r_{n_{D_{p}}, n_{D_{q}}}^{p, c}<t_{n_{D_{p}}, n_{D_{q}}}^{p, c}$ and $r_{n_{D_{p}}, n_{D_{q}}}^{q, c}<t_{n_{D_{p}}, n_{D_{q}}}^{q, c}$. Then, transform $\dot{e}_{n_{D_{p}}, n_{D_{q}}}^{p, c}$ and $\dot{e}_{n_{D_{p}}, n_{D_{q}}}^{q, c}$ into interval 2-tuple linguistic variables $e_{n_{D_{p}}, n_{D_{q}}}^{p, c}=\left[\left(r_{n_{D_{p}}, n_{D_{q}}}^{p, c}, 0\right),\left(t_{n_{D_{p}}, n_{D_{q}}}^{p, c}, 0\right)\right]$ and $e_{n_{D_{p}}, n_{D_{q}}}^{q, c}=\left[\left(r_{n_{D_{p}}, n_{D_{q}}}^{q, c}, 0\right),\left(t_{n_{D_{p}}, n_{D_{q}}}^{q, c}, 0\right)\right]$.

Step 1.4: For any pair of alternatives $\left(A_{n_{D_{p}}}^{D_{p}}, A_{n_{D_{q}}}^{D_{q}}\right)$, its collaborative performance evaluation regarding $C C_{c}$ is calculated as uncertainty and DMs' limited knowledge and experiences, it is difficult for DMs to express their judgements by numerical values with full determinacy and confidence in the EDM processes. In these cases, multi-granularity interval linguistic variables are more suitable to capture fuzzy, uncertain and diversified evaluation information in reference comparisons. With the aid of interval 2-tuple linguistic model, this study employs multi-granularity interval linguistic variables to represent DMs' preferences on reference comparisons and proposes the ITL-BWM to derive the criteria weights.

Step 2.1: Each $D M_{j}(j=1,2, \ldots, J)$ determines the best (most important) and the worst (least important) criteria

$E_{c}^{\left(A_{n_{p}}^{D_{p}}, A_{n_{D_{q}}}^{D_{q}}\right)}=\lambda_{p} \cdot e_{n_{D_{p}}, n_{D_{q}}}^{p, c}+\lambda_{q} \cdot e_{n_{D_{p}}, n_{D_{q}}}^{q, c}, c=1,2, \ldots, C, n_{D_{p}}=1,2, \ldots, N_{D_{p}}, n_{D_{q}}=1,2, \ldots, N_{D_{q}}, p, q=1,2, \ldots, J, p<q$.

Step 1.5: For any multi-alternative combination $A_{n_{D_{1}}}^{D_{1}} A_{n_{D_{2}}}^{D_{2}} \ldots A_{n_{D_{J}}}^{D_{J}}$, its collaborative performance evaluation regarding $C C_{c}$ is determined by from his/her perspective.

Step 2.2: Each $D M_{j}(j=1,2, \ldots, J)$ chooses a linguistic term set $\bar{S}^{j}$ from the multi-granularity ones and expresses his/ her preference degree of the best criterion $B$ over each crite-

$$
E_{c}^{A_{n_{1}}^{D_{1}} A_{n_{D_{2}}}^{D_{2}} \cdots A_{n_{D_{J}}}^{D_{J}}}=\sum_{p=1}^{J-1} \sum_{q=p+1}^{J} \lambda_{p q} \cdot E_{c}^{\left(A_{n_{D}}^{D_{p}}, A_{D_{D_{q}}}^{D_{q}}\right)}, c=1,2, \ldots, C, n_{D_{p}}=1,2, \ldots, N_{D_{p}}, n_{D_{q}}=1,2, \ldots, N_{D_{q}}, p, q=1,2, \ldots, J, p<q
$$

$$
\lambda_{p q}=\frac{\lambda_{p} \lambda_{q}}{\sum_{p=1}^{J-1} \sum_{q=p+1}^{J} \lambda_{p} \lambda_{q}}, p, q=1,2, \ldots, J, p<q
$$

where $\lambda_{p q}$ is the normalized joint weight of $D M_{p}$ and $D M_{q}$.

From this, the collaborative performance evaluations of all the multi-alternative combinations can be obtained as rion $n(n=1,2, \ldots, N)$ using an interval linguistic variable $\dot{a}_{B n}^{j}=\left[r_{B n}^{j}, t_{B n}^{j}\right]$, with $r_{B n}^{j}, t_{B n}^{j} \in \bar{S}^{j}$ and $r_{B n}^{j} \leq t_{B n}^{j}$. The obtained interval linguistic best-to-others (ILBO) vector from the viewpoint of $D M_{j}$ is denoted as $\dot{A}_{B}^{j}=\left(\dot{a}_{B 1}^{j}, \dot{a}_{B 2}^{j}, \ldots, \dot{a}_{B N}^{j}\right)$.

Step 2.3: Each $D M_{j}(j=1,2, \ldots, J)$ provides his/her preference degree of each criterion $n(n=1,2, \ldots, N)$ over the worst criterion $W$ using an interval linguistic variable $\dot{a}_{n W}^{j}=\left[r_{n W}^{j}, t_{n W}^{j}\right]$, with $r_{n W}^{j}, t_{n W}^{j} \in \bar{S}^{j}$ and $r_{n W}^{j} \leq t_{n W}^{j}$. The obtained interval linguistic others-to-worst

$$
\begin{aligned}
& \begin{array}{llllll}
C C_{1} & \cdots & C C_{c} & \cdots & C C_{C}
\end{array}
\end{aligned}
$$

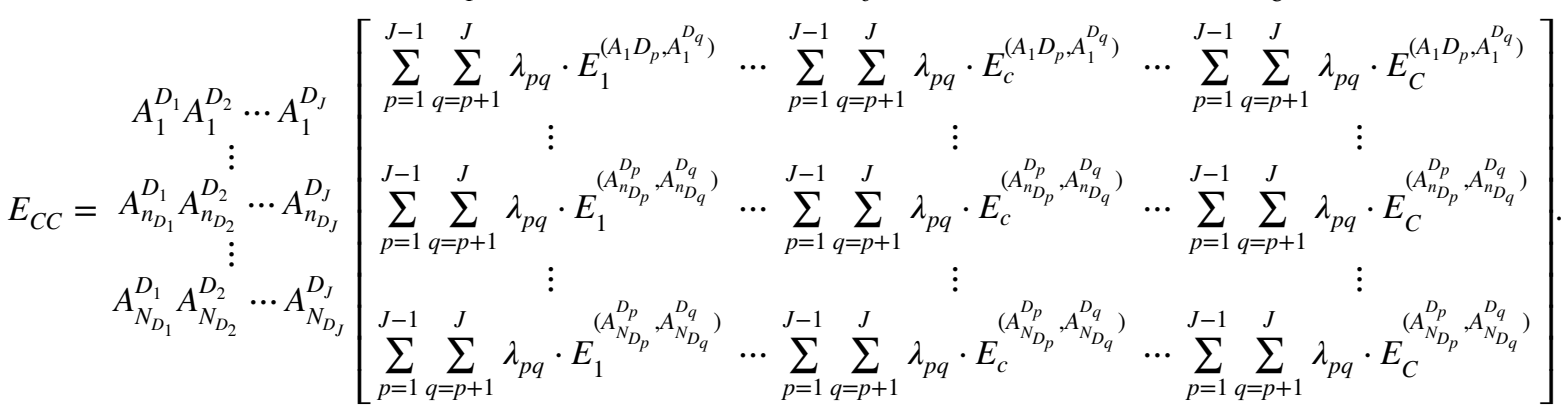

$$
\begin{aligned}
& n_{D_{p}}=1,2, \cdots, N_{D_{p}}, n_{D_{q}}=1,2, \cdots, N_{D_{q}}, p, q=1,2, \cdots, J, p<q
\end{aligned}
$$

\section{Stage 2: Determine criteria weights using the ITL-BWM}

In the traditional BWM, the reference comparisons for the best criterion and worst criterion are described by a 1-9 scale. However, because of the inherent complexity and
(ILOW) vector from $D M_{j}$ 's viewpoint is represented as $\dot{A}_{W}^{j}=\left(\dot{a}_{1 W}^{j}, \dot{a}_{2 W}^{j}, \ldots, \dot{a}_{N W}^{j}\right)$.

Step 2.4: Transform the ILBO and ILOW vectors into interval 2-tuple linguistic best-to-others (ITLBO) vector 
$A_{B}^{j}=\left(a_{B 1}^{j}, a_{B 2}^{j}, \ldots, a_{B N}^{j}\right)$ and interval 2-tuple linguistic others-to-worst (ITLOW) vector $A_{W_{j}}^{j}=\left(a_{1 W}^{j}, a_{2 W}^{j}, \ldots, a_{N W}^{j}\right)$, where $a_{B n}^{j}=\left[\left(r_{B n}^{j}, 0\right),\left(t_{B n}^{j}, 0\right)\right]$ and $a_{n W}^{j}=\left[\left(r_{n W}^{j}, 0\right),\left(t_{n W}^{j}, 0\right)\right]$, with $j=1,2, \ldots, J$ and $n=1,2, \ldots, N$.

Step 2.5: Compute the optimal weights $\left(w_{1}^{*}, w_{2}^{*}, \ldots, w_{N}^{*}\right)$.

The optimal interval weights of criteria are determined such that the maximum absolute differences $\left|\frac{w_{B}}{w_{n}}-U\left(\Delta^{-1}\left(a_{B n}^{j}\right)\right)\right|$ and $\left|\frac{w_{n}}{w_{W}}-U\left(\Delta^{-1}\left(a_{n W}^{j}\right)\right)\right|$ for all $n$ are minimized, which can be formulated as the following nonlinear programming model:

$\min Z=\sum_{j}^{J} \lambda_{j} \varepsilon_{j}$

$\left\{\begin{array}{l}\left|\frac{w_{B}}{w_{n}}-U\left(\Delta^{-1}\left(a_{B n}^{j}\right)\right)\right| \leq \varepsilon_{j}, \text { for all } n, \\ \left|\frac{w_{n}}{w_{W}}-U\left(\Delta^{-1}\left(a_{n W}^{j}\right)\right)\right| \leq \varepsilon_{j}, \text { for all } n,\end{array}\right\}$ for all $j$

where $w_{B}=\left[l_{B}^{w}, u_{B}^{w}\right], \quad w_{n}=\left[l_{n}^{w}, u_{n}^{w}\right], \quad w_{W}=\left[l_{W}^{w}, u_{W}^{w}\right]$, $\varepsilon_{j}=\left[l_{j}^{\varepsilon}, u_{j}^{\varepsilon}\right], \lambda_{j}$ is the weight of $D M_{j}, \sum_{\vartheta=1, \vartheta \neq n}^{N} u_{\vartheta}^{w}+l_{n}^{w} \geq 1$ and $\sum_{\vartheta=1, \vartheta \neq n}^{N} l_{\vartheta}^{w}+u_{n}^{w} \leq 1$ are the constraints of interval weights for reducing the redundant solution space [54], $U\left(\Delta^{-1}\left(a_{B n}^{j}\right)\right)=\left[\ell^{g \cdot \Delta^{-1}\left(r_{B n}^{j}, 0\right)}, \ell^{g \cdot \Delta^{-1}\left(t_{B n}^{j}, 0\right)}\right]$

a $n$ d $U\left(\Delta^{-1}\left(a_{n W}^{j}\right)\right)=\left[\ell^{g \cdot \Delta^{-1}\left(r_{n W}^{j}, 0\right)}, \ell^{g \cdot \Delta^{-1}\left(t_{n W}^{j}, 0\right)}\right]$ are the utility values of cognitive linguistic evaluations $a_{B n}^{j}$ and $a_{n W}^{j}$, $\ell=\sqrt[g]{\text { Best/Worst }}$ is the objective importance ratio of two adjacent terms considering that different DMs may have different cognitive standards towards the MCDM problem [27, 28], $g$ represents the granularity of linguistic term set, and Best/Worst is provided by the decision maker and stands for the maximum difference in the decision maker's evaluation information.

According to the study of Rezaei [51], we can minimize the maximum among the set of $\left\{\left|w_{B}-U\left(\Delta^{-1}\left(a_{B n}^{j}\right)\right) \cdot w_{n}\right|,\left|w_{n}-U\left(\Delta^{-1}\left(a_{n W}^{j}\right)\right) \cdot w_{W}\right|\right\}$ instead of $\left\{\left|\frac{w_{B}}{w_{n}}-U\left(\Delta^{-1}\left(a_{B n}^{j}\right)\right)\right|,\left|\frac{w_{n}}{w_{W}}-U\left(\Delta^{-1}\left(a_{n W}^{j}\right)\right)\right|\right\}$.
Simultaneously, considering $l_{j}^{\varepsilon}<u_{j}^{\varepsilon}$ and assuming $\varepsilon_{j}^{*}=\left[\chi_{j}^{*}, \chi_{j}^{*}\right], \chi_{j}^{*} \leq l_{j}^{\varepsilon}$, model (14) can be converted into the following interval fuzzy mathematical programming model:

$$
\begin{aligned}
& \min Z=\sum_{j}^{J} \lambda_{j} \varepsilon_{j}^{*}
\end{aligned}
$$

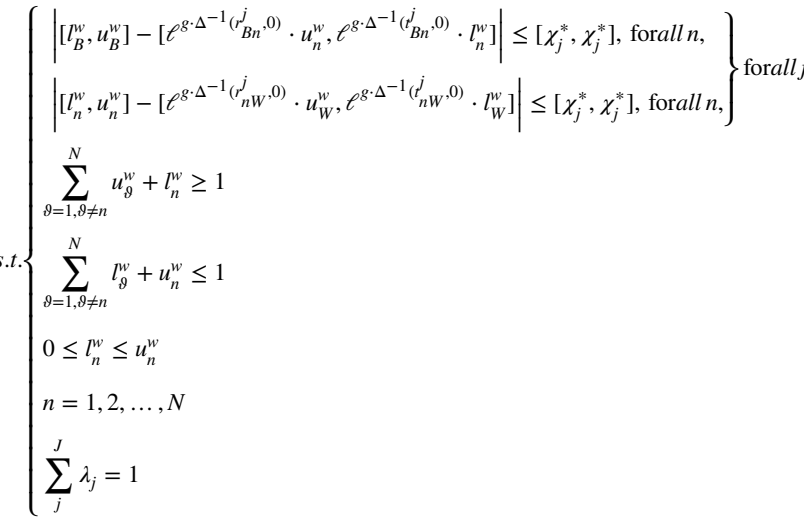

By solving model (15), the optimal interval weights $\left(\bar{w}_{1}^{*}, \bar{w}_{2}^{*}, \cdots, \bar{w}_{N}^{*}\right)$ and $\left(\varepsilon_{1}^{*}, \varepsilon_{2}^{*}, \cdots, \varepsilon_{J}^{*}\right)$ can be obtained. $\sum_{j}^{J} \lambda_{j} \varepsilon_{j}^{*}$ can be interpreted as a measure of the consistency level of group decisions. A value of $\sum_{j}^{J} \lambda_{j} \varepsilon_{j}^{*}$ close to zero shows a high consistency level. Then, the optimal weights $\left(w_{1}^{*}, w_{2}^{*}, \ldots, w_{N}^{*}\right)$ are derived as follows:

$w_{n}^{*}=\operatorname{mean}\left(\bar{w}_{n}^{*}\right)=\left(\bar{l}_{n}^{w *}+\bar{u}_{n}^{w *}\right) / 2$,

where $\left[\bar{l}_{n}^{w *}, \bar{u}_{n}^{w *}\right]=\bar{w}_{n}^{*}$, with $n=1,2, \ldots, N$.

By now, the weights of individual and collaborative criteria can be calculated through above developed ITL-BWM.

\section{Stage 3: Derive the priority ranking using the ITL-TODIM}

Because EDM problems are usually risky and uncertain, it is preferred to consider DMs' psychological behaviours. Therefore, in this stage, an ITL-TODIM approach is proposed to derive the priority ranking of solutions, which is completed by the following steps.

Step 3.1: Let $x_{a n}=\left[\left(r_{a n}, \alpha_{a n}\right),\left(t_{a n}, \varepsilon_{a n}\right)\right]$ and $x_{b n}=\left[\left(r_{b n}, \alpha_{b n}\right),\left(t_{b n}, \varepsilon_{b n}\right)\right]$ be respectively the performance evaluations of solutions $A_{a}$ (such as a multi-alternative combination) and $A_{b}$ (such as another multi-alternative combination) concerning criterion $n$, with $a, b=1,2, \ldots, M$ and $n=1,2, \ldots, N$. Let $\gamma_{a n}$ and $\gamma_{b n}$ be the random variables in interval numbers $\Delta^{-1}\left(x_{a n}\right)$ and $\Delta^{-1}\left(x_{b n}\right)$, respectively, and their probability density functions are denoted as. 
$f_{a n}(x)=\left\{\begin{array}{l}\frac{1}{\Delta^{-1}\left(t_{a n}, \varepsilon_{a n}\right)-\Delta^{-1}\left(r_{a n}, \alpha_{a n}\right)}, \Delta^{-1}\left(r_{a n}, \alpha_{a n}\right) \leq x \leq \Delta^{-1}\left(t_{a n}, \varepsilon_{a n}\right) \\ 0, \text { otherwise }\end{array}, a=1,2, \ldots, M, n=1,2, \ldots, N\right.$,

$f_{b n}(x)=\left\{\begin{array}{l}\frac{1}{\Delta^{-1}\left(t_{b n}, \varepsilon_{b n}\right)-\Delta^{-1}\left(r_{b n}, \alpha_{b n}\right)}, \Delta^{-1}\left(r_{b n}, \alpha_{b n}\right) \leq x \leq \Delta^{-1}\left(t_{b n}, \varepsilon_{b n}\right) \\ 0, \text { otherwise }\end{array}, b=1,2, \ldots, M, n=1,2, \ldots, N\right.$.

Step 3.2: Calculate the gains and losses.

If $n$ is a benefit criterion, the gain degree $\hat{g}_{a b}^{n}$ of $A_{a}$ relative to $A_{b}$ is expressed as the expectation of $\gamma_{a n}-\gamma_{b n}$ for $\gamma_{a n}>\gamma_{b n}$, i.e.,

$\hat{g}_{a b}^{n}=\iint_{\gamma_{a n}>\gamma_{b n}}^{x \in \Delta^{-1}\left(x_{a n}\right), y \in \Delta^{-1}\left(x_{b n}\right)}(x-y) f_{a n}(x) f_{b n}(y) d x d y=\int_{x \in \Delta^{-1}\left(x_{a n}\right)} f_{a n}(x) \int_{\gamma_{a n}>\gamma_{b n}}^{y \in \Delta^{-1}\left(x_{b n}\right)}(x-y) f_{b n}(y) d y d x$,

$a, b=1,2, \ldots, M, n=1,2, \ldots, N$.

The loss degree $\hat{l}_{a b}^{n}$ of $A_{a}$ relative to $A_{b}$ is expressed as the expectation of $\gamma_{a n}-\gamma_{b n}$ for $\gamma_{a n} \leq \gamma_{b n}$, i.e.,

$\hat{l}_{a b}^{n}=\iint_{\gamma_{a n} \leq \gamma_{b n}}^{x \in \Delta^{-1}\left(x_{a n}\right), y \in \Delta^{-1}\left(x_{b n}\right)}(x-y) f_{a n}(x) f_{b n}(y) d x d y=\int_{x \in \Delta^{-1}\left(x_{a n}\right)} f_{a n}(x) \int_{\gamma_{a n} \leq \gamma_{b n}}^{y \in \Delta^{-1}\left(x_{b n}\right)}(x-y) f_{b n}(y) d y d x$,

$a, b=1,2, \ldots, M, n=1,2, \ldots, N$.

Similarly, if $n$ is a cost criterion, the gain degree $\hat{g}_{a b}^{n}$ and loss degree $\hat{l}_{a b}^{n}$ of $A_{a}$ relative to $A_{b}$ are respectively expressed

as

$\hat{g}_{a b}^{n}=\iint_{\gamma_{a n}<\gamma_{b n}}^{x \in \Delta^{-1}\left(x_{a n}\right), y \in \Delta^{-1}\left(x_{b n}\right)}(y-x) f_{a n}(x) f_{b n}(y) d x d y=\int_{x \in \Delta^{-1}\left(x_{a n}\right)} f_{a n}(x) \int_{\gamma_{a n}<\gamma_{b n}}^{y \in \Delta^{-1}\left(x_{b n}\right)}(y-x) f_{b n}(y) d y d x$,

$a, b=1,2, \ldots, M, n=1,2, \ldots, N$,

$\hat{l}_{a b}^{n}=\iint_{\gamma_{a n} \geq \gamma_{b n}}^{x \in \Delta^{-1}\left(x_{a n}\right), y \in \Delta^{-1}\left(x_{b n}\right)}(y-x) f_{a n}(x) f_{b n}(y) d x d y=\int_{x \in \Delta^{-1}\left(x_{a n}\right)} f_{a n}(x) \int_{\gamma_{a n} \geq \gamma_{b n}}^{y \in \Delta^{-1}\left(x_{b n}\right)}(y-x) f_{b n}(y) d y d x$,

$a, b=1,2, \ldots, M, n=1,2, \ldots, N$.

Thus, the gain matrix $\hat{g}^{n}=\left[\hat{g}_{a b}^{n}\right]_{M \times M}$ and loss matrix $\hat{l}^{n}=\left[\hat{l}_{a b}^{n}\right]_{M \times M}$ with respect to criterion $n$ can be obtained, where $\hat{g}_{z z}^{n}=\hat{l}_{z z}^{n}=0$, with $z=1,2, \ldots, M$ and $n=1,2, \ldots, N$.

Step 3.3: For analysis and computation convenience, the matrices $\hat{g}^{n}=\left[\hat{g}_{a b}^{n}\right]_{M \times M}$ and $\hat{l}^{n}=\left[\hat{l}_{a b}^{n}\right]_{M \times M}$ need to be normalized. Let the normalized matrices be $\tilde{g}^{n}=\left[\tilde{g}_{a b}^{n}\right]_{M \times M}$ and $\tilde{l}^{n}=\left[\tilde{l}_{a b}^{n}\right]_{M \times M}$, where $\tilde{g}_{a b}^{n}$ and $\tilde{l}_{a b}^{n}$ can be determined as

$$
\tilde{g}_{a b}^{n}=\frac{\hat{g}_{a b}^{n}}{\max _{a, b=\{1,2, \cdots, M\}}\left\{\hat{g}_{a b}^{n}\right\}}, a, b=1,2, \cdots, M, n=1,2, \cdots, N,
$$

$\tilde{l}_{a b}^{n}=\frac{\hat{l}_{a b}^{n}}{\max _{a, b=\{1,2, \cdots, M\}}\left\{\left|\hat{l}_{a b}^{n}\right|\right\}}, a, b=1,2, \ldots, M, n=1,2, \ldots, N$, 
Step 3.4: Based on the function of dominance degree in the classical TODIM method [14], the positive dominance degree $\psi_{a b}^{n+}$ and negative dominance degree $\psi_{a b}^{n-}$ of $A_{a}$ over $A_{b}$ regarding criterion $n$ can be computed by

$\psi_{a b}^{n+}=\sqrt{\frac{\tilde{g}_{a b}^{n} w_{n}}{w_{r} \sum_{n=1}^{N}\left(w_{n} / w_{r}\right)}}, a, b=1,2, \ldots, M, n=1,2, \ldots, N$,

$\psi_{a b}^{n-}=-\frac{1}{\theta} \sqrt{\frac{-\tilde{l}_{a b}^{n} w_{r}}{w_{n}} \sum_{n=1}^{N}\left(w_{n} / w_{r}\right)}, a, b=1,2, \ldots, M, n=1,2, \ldots, N$,

where $w_{n}$ denotes the weight of criterion $n$, $w_{r}=\max \left\{w_{n} \mid n=\{1,2, \ldots, N\}\right\}$, and $\theta>0$ is the attenuation factor of loss. $\theta$ can measure the loss aversion degree of DMs. Apparently, $0 \leq \psi_{a b}^{n+}<1$ and $\psi_{a b}^{n-} \leq 0$.

Step 3.5: Construct the dominance degree matrix $\hbar=\left[\hbar_{a b}\right]_{M \times M}$, where $\hbar_{a b}$ represents the dominance degree of $A_{a}$ over $A_{b}$ and is expressed by

$\hbar_{a b}=\sum_{n=1}^{N} \psi_{a b}^{n+}+\sum_{n=1}^{N} \psi_{a b}^{n-}, a, b=1,2, \ldots, M$.

Step 3.6: Derive the overall dominance value $\xi\left(A_{a}\right)$ of $A_{a}$ over other solutions by

$\xi\left(A_{a}\right)=\frac{\sum_{b=1}^{M} \hbar_{a b}-\min _{a \in\{1,2, \cdots, M\}}\left\{\sum_{b=1}^{M} \hbar_{a b}\right\}}{\max _{a \in\{1,2, \cdots, M\}}\left\{\sum_{b=1}^{n} \hbar_{a b}\right\}-\min _{a \in\{1,2, \cdots, M\}}\left\{\sum_{b=1}^{M} \hbar_{a b}\right\}}, a=1,2, \ldots, M$.
According to $\xi\left(A_{a}\right)$, the priority ranking of solutions can be determined. The larger $\xi\left(A_{a}\right)$ is, the better $A_{a}$ will be.

At this point, based on the individual/collaborative performance evaluations obtained in Stage $\mathbf{1}$ and weights of individual/collaborative criteria obtained in Stage 2, the overall dominance values $\xi^{I C}\left(A_{n_{D_{1}}}^{D_{1}} A_{n_{D_{2}}}^{D_{2}} \cdots A_{n_{D_{J}}}^{D_{J}}\right)$

Table 1 Emergency alternatives of three departments

\begin{tabular}{ll}
\hline Department & Alternative \\
\hline$D_{1}$ & $A_{1}^{D_{1}}:$ normal traffic without restriction \\
& $A_{2}^{D_{1}}:$ partial traffic restrictions \\
$D_{2}$ & $A_{1}^{D_{2}}:$ medium-duty trucks for emergency supply \\
& transportation \\
& $A_{2}^{D_{2}}:$ light-duty trucks for emergency supply transpor- \\
& tation \\
$D_{3}$ & $A_{1}^{D_{3}}:$ large-scale machinery and equipment \\
& $A_{2}^{D_{3}}:$ medium-scale machinery and equipment \\
\hline
\end{tabular}

$\xi^{C C}\left(A_{n_{D_{1}}}^{D_{1}} A_{n_{D_{2}}}^{D_{2}} \cdots A_{n_{D_{J}}}^{D_{J}}\right)$ concerning individual/collaborative criteria of any multi-alternative combination $A_{n_{D_{1}}}^{D_{1}} A_{n_{D_{2}}}^{D_{2}} \cdots A_{n_{D_{J}}}^{D_{J}}$ can be derived by using the above proposed ITL-TODIM method. Then, the comprehensive dominance value $\xi\left(A_{n_{D_{1}}}^{D_{1}} A_{n_{D_{2}}}^{D_{2}} \cdots A_{n_{D_{J}}}^{D_{J}}\right)$ of $A_{n_{D_{1}}}^{D_{1}} A_{n_{D_{2}}}^{D_{2}} \cdots A_{n_{D_{J}}}^{D_{J}}$ is calculated to rank the multi-alternative combinations by the following equation:

$$
\begin{aligned}
\xi\left(A_{n_{D_{1}}}^{D_{1}} A_{n_{D_{2}}}^{D_{2}} \cdots A_{n_{D_{J}}}^{D_{J}}\right)= & (1-\sigma) \xi^{I C}\left(A_{n_{D_{1}}}^{D_{1}} A_{n_{D_{2}}}^{D_{2}} \cdots A_{n_{D_{J}}}^{D_{J}}\right) \\
& +\sigma \xi^{C C}\left(A_{n_{D_{1}}}^{D_{1}} A_{n_{D_{2}}}^{D_{2}} \cdots A_{n_{D_{J}}}^{D_{J}}\right), n_{D_{j}} \\
= & 1,2, \cdots, N_{D_{j}}, j=1,2, \cdots, J
\end{aligned}
$$

where $\sigma \in[0,1]$ is a control parameter. $\xi\left(A_{n_{D_{1}}}^{D_{1}} A_{n_{D_{2}}}^{D_{2}} \cdots A_{n_{D_{J}}}^{D_{J}}\right)$ can trade off the overall dominance values with respect to individual criteria and collaborative criteria by changing the value of $\sigma$.

\section{Numerical example}

This section provides a numerical example to illustrate the application and feasibility of the proposed method.

Suppose that a landslide accident occurs and causes some casualties and economic losses. For simplicity, three

Table 2 Interval 2-tuple linguistic evaluations of the alternative performances regarding individual criteria

\begin{tabular}{lllll}
\hline $\begin{array}{llll}\text { Decision } \\
\text { maker }\end{array}$ & $\begin{array}{l}\text { Alterna- } \\
\text { tive }\end{array}$ & \multicolumn{4}{l}{ Individual criteria } \\
\cline { 3 - 5 } & & $I C_{1}$ & $I C_{2}$ & $I C_{3}$ \\
\hline$D M_{1}$ & $A_{1}^{D_{1}}$ & {$\left[\left(\mathrm{a}_{1}, 0\right),\left(\mathrm{a}_{1}, 0\right)\right]$} & {$\left[\left(\mathrm{a}_{3}, 0\right),\left(\mathrm{a}_{3}, 0\right)\right]$} & {$\left[\left(\mathrm{a}_{1}, 0\right),\left(\mathrm{a}_{3}, 0\right)\right]$} \\
& $A_{2}^{D_{1}}$ & {$\left[\left(\mathrm{a}_{2}, 0\right),\left(\mathrm{a}_{3}, 0\right)\right]$} & {$\left[\left(\mathrm{a}_{1}, 0\right),\left(\mathrm{a}_{2}, 0\right)\right]$} & {$\left[\left(\mathrm{a}_{3}, 0\right),\left(\mathrm{a}_{3}, 0\right)\right]$} \\
$D M_{2}$ & $A_{1}^{D_{2}}$ & {$\left[\left(\mathrm{~b}_{3}, 0\right),\left(\mathrm{b}_{5}, 0\right)\right]$} & {$\left[\left(\mathrm{b}_{4}, 0\right),\left(\mathrm{b}_{5}, 0\right)\right]$} & {$\left[\left(\mathrm{b}_{4}, 0\right),\left(\mathrm{b}_{6}, 0\right)\right]$} \\
& $A_{2}^{D_{2}}$ & {$\left[\left(\mathrm{~b}_{5}, 0\right),\left(\mathrm{b}_{5}, 0\right)\right]$} & {$\left[\left(\mathrm{b}_{5}, 0\right),\left(\mathrm{b}_{6}, 0\right)\right]$} & {$\left[\left(\mathrm{b}_{4}, 0\right),\left(\mathrm{b}_{5}, 0\right)\right]$} \\
$D M_{3}$ & $A_{1}^{D_{3}}$ & {$\left[\left(\mathrm{a}_{2}, 0\right),\left(\mathrm{a}_{2}, 0\right)\right]$} & {$\left[\left(\mathrm{a}_{2}, 0\right),\left(\mathrm{a}_{3}, 0\right)\right]$} & {$\left[\left(\mathrm{a}_{4}, 0\right),\left(\mathrm{a}_{4}, 0\right)\right]$} \\
& $A_{2}^{D_{3}}$ & {$\left[\left(\mathrm{a}_{3}, 0\right),\left(\mathrm{a}_{4}, 0\right)\right]$} & {$\left[\left(\mathrm{a}_{3}, 0\right),\left(\mathrm{a}_{3}, 0\right)\right]$} & {$\left[\left(\mathrm{a}_{2}, 0\right),\left(\mathrm{a}_{3}, 0\right)\right]$} \\
\hline
\end{tabular}


Table 3 Individual performance evaluations of multi-alternative combinations
Table 4 Collaborative performance evaluations of alternative pairs
Table 5 Collaborative performance evaluations of multi-alternative combinations

\begin{tabular}{llll}
\hline $\begin{array}{l}\text { Multi-alternative com- } \\
\text { bination }\end{array}$ & \multicolumn{2}{l}{ Individual criteria } & \\
\cline { 2 - 4 } & $I C_{1}$ & $I C_{2}$ & $I C_{3}$ \\
\hline$A_{1}^{D_{1}} A_{1}^{D_{2}} A_{1}^{D_{3}}$ & $\Delta([0.4250,0.5417])$ & $\Delta([0.6333,0.7792])$ & $\Delta([0.6583,0.9250])$ \\
$A_{1}^{D_{1}} A_{1}^{D_{2}} A_{2}^{D_{3}}$ & $\Delta([0.5125,0.7167])$ & $\Delta([0.7208,0.7792])$ & $\Delta([0.4833,0.8375])$ \\
$A_{1}^{D_{1}} A_{2}^{D_{2}} A_{1}^{D_{3}}$ & $\Delta([0.5417,0.5417])$ & $\Delta([0.6917,0.8375])$ & $\Delta([0.6583,0.8667])$ \\
$A_{1}^{D_{1}} A_{2}^{D_{2}} A_{2}^{D_{3}}$ & $\Delta([0.6292,0.7167])$ & $\Delta([0.7792,0.8375])$ & $\Delta([0.4833,0.7792])$ \\
$A_{2}^{D_{1}} A_{1}^{D_{2}} A_{1}^{D_{3}}$ & $\Delta([0.5000,0.6917])$ & $\Delta([0.4833,0.7042])$ & $\Delta([0.8083,0.9250])$ \\
$A_{2}^{D_{1}} A_{1}^{D_{2}} A_{2}^{D_{3}}$ & $\Delta([0.5875,0.8667])$ & $\Delta([0.5708,0.7042])$ & $\Delta([0.6333,0.8375])$ \\
$A_{2}^{D_{1}} A_{2}^{D_{2}} A_{1}^{D_{3}}$ & $\Delta([0.6167,0.6917])$ & $\Delta([0.5417,0.7625])$ & $\Delta([0.8083,0.8667])$ \\
$A_{2}^{D_{1}} A_{2}^{D_{2}} A_{2}^{D_{3}}$ & $\Delta([0.7042,0.8667])$ & $\Delta([0.6292,0.7625])$ & $\Delta([0.6333,0.7792])$ \\
\hline & & & \\
\hline
\end{tabular}

\begin{tabular}{llll}
\hline Pair of alternatives & \multicolumn{2}{l}{ Collaborative criteria } & \\
\cline { 2 - 4 } & $C C_{1}$ & $C C_{2}$ & $C C_{3}$ \\
\hline$\left(A_{1}^{D_{1}}, A_{1}^{D_{2}}\right)$ & $\Delta([0.2500,0.3250])$ & $\Delta([0.3250,0.3833])$ & $\Delta([0.1333,0.3250])$ \\
$\left(A_{1}^{D_{1}}, A_{2}^{D_{2}}\right)$ & $\Delta([0.3250,0.4583])$ & $\Delta([0.4000,0.5167])$ & $\Delta([0.3250,0.3250])$ \\
$\left(A_{1}^{D_{1}}, A_{1}^{D_{3}}\right)$ & $\Delta([0.0000,0.0875])$ & $\Delta([0.1625,0.2500])$ & $\Delta([0.0875,0.1625])$ \\
$\left(A_{1}^{D_{1}}, A_{2}^{D_{3}}\right)$ & $\Delta([0.2375,0.3250])$ & $\Delta([0.3250,0.4000])$ & $\Delta([0.1625,0.3250])$ \\
$\left(A_{2}^{D_{1}}, A_{1}^{D_{2}}\right)$ & $\Delta([0.4000,0.4583])$ & $\Delta([0.3833,0.4583])$ & $\Delta([0.3250,0.3250])$ \\
$\left(A_{2}^{D_{1}}, A_{2}^{D_{2}}\right)$ & $\Delta([0.4000,0.5333])$ & $\Delta([0.5167,0.5167])$ & $\Delta([0.4583,0.5333])$ \\
$\left(A_{2}^{D_{1}}, A_{1}^{D_{3}}\right)$ & $\Delta([0.4125,0.4875])$ & $\Delta([0.3250,0.3250])$ & $\Delta([0.2375,0.3250])$ \\
$\left(A_{2}^{D_{1}}, A_{2}^{D_{3}}\right)$ & $\Delta([0.4875,0.5625])$ & $\Delta([0.4125,0.4875])$ & $\Delta([0.3250,0.4000])$ \\
$\left(A_{1}^{D_{2}}, A_{1}^{D_{3}}\right)$ & $\Delta([0.4958,0.5833])$ & $\Delta([0.4375,0.5542])$ & $\Delta([0.1458,0.2625])$ \\
$\left(A_{1}^{D_{2}}, A_{2}^{D_{3}}\right)$ & $\Delta([0.4375,0.4958])$ & $\Delta([0.4375,0.4958])$ & $\Delta([0.2917,0.4375])$ \\
$\left(A_{2}^{D_{2}}, A_{1}^{D_{3}}\right)$ & $\Delta([0.3500,0.5250])$ & $\Delta([0.3500,0.4958])$ & $\Delta([0.3500,0.5250])$ \\
$\left(A_{2}^{D_{2}}, A_{2}^{D_{3}}\right)$ & $\Delta([0.2917,0.4958])$ & $\Delta([0.3500,0.4375])$ & $\Delta([0.4375,0.5833])$ \\
\hline
\end{tabular}

\begin{tabular}{llll}
\hline $\begin{array}{l}\text { Multi-alternative combi- } \\
\text { nations }\end{array}$ & Collaborative criteria & & \\
\cline { 2 - 4 } & $C C_{1}$ & $C C_{2}$ & $C C_{3}$ \\
\hline$A_{1}^{D_{1}} A_{1}^{D_{2}} A_{1}^{D_{3}}$ & $\Delta([0.2616,0.3452])$ & $\Delta([0.3151,0.4042])$ & $\Delta([0.1235,0.2507])$ \\
$A_{1}^{D_{1}} A_{1}^{D_{2}} A_{2}^{D_{3}}$ & $\Delta([0.2316,0.3658])$ & $\Delta([0.3066,0.4248])$ & $\Delta([0.2592,0.3474])$ \\
$A_{1}^{D_{1}} A_{2}^{D_{2}} A_{1}^{D_{3}}$ & $\Delta([0.3151,0.3879])$ & $\Delta([0.3664,0.4300])$ & $\Delta([0.2009,0.3664])$ \\
$A_{1}^{D_{1}} A_{2}^{D_{2}} A_{2}^{D_{3}}$ & $\Delta([0.2851,0.4300])$ & $\Delta([0.3579,0.4507])$ & $\Delta([0.3151,0.4202])$ \\
$A_{2}^{D_{1}} A_{1}^{D_{2}} A_{1}^{D_{3}}$ & $\Delta([0.4393,0.5136])$ & $\Delta([0.3849,0.4515])$ & $\Delta([0.2314,0.3020])$ \\
$A_{2}^{D_{1}} A_{1}^{D_{2}} A_{2}^{D_{3}}$ & $\Delta([0.3855,0.5158])$ & $\Delta([0.3947,0.4485])$ & $\Delta([0.3487,0.4645])$ \\
$A_{2}^{D_{1}} A_{2}^{D_{2}} A_{1}^{D_{3}}$ & $\Delta([0.4414,0.5050])$ & $\Delta([0.4125,0.4814])$ & $\Delta([0.3127,0.3901])$ \\
$A_{2}^{D_{1}} A_{2}^{D_{2}} A_{2}^{D_{3}}$ & $\Delta([0.3877,0.5287])$ & $\Delta([0.4224,0.4783])$ & $\Delta([0.4086,0.5096])$ \\
& & &
\end{tabular}


emergency departments are considered for rescue and relief: traffic management department $\left(D_{1}\right)$, emergency service department $\left(D_{2}\right)$, and construction and repair department $\left(D_{3}\right) . D M_{1}, D M_{2}$ and $D M_{3}$ are three DMs respectively representing $D_{1}, D_{2}$ and $D_{3}$ in the decision making process, whose weighting vector is $\lambda=\{0.3,0.35,0.35\}$. The emergency alternatives supplied by above three departments are listed in Table 1. To select a desirable multi-alternative combination for coping with this accident, some individual criteria, such as the cost $\left(I C_{1}\right.$, cost criterion), operation feasibility $\left(I C_{2}\right)$ and rescue effect $\left(I C_{3}\right)$, and some collaborative criteria, such as the program complementarity $\left(C C_{1}\right)$, resource sharing $\left(C C_{2}\right)$ and action coordination $\left(C C_{3}\right)$, are taken into account.

In what follows, the proposed approach is applied to find the best multi-alternative combination.

\section{Stage 1: Obtain the individual and collaborative perfor- mance evaluations}

(1) Individual performance evaluations

The three DMs adopt different linguistic term sets to assess the performances of alternatives given by their own departments with respect to individual criteria. Specifically, $D M_{1}$ and $D M_{3}$ provide their assessments in a set of 5 labels, $S^{5} ; D M_{2}$ expresses his assessments in a set of 7 labels, $S^{7}$. These linguistic term sets are denoted as follows:

$S^{5}=\left\{\mathrm{a}_{0}=\right.$ very low/poor, $\mathrm{a}_{1}=$ low/poor, $\mathrm{a}_{2}=$ fair, $\mathrm{a}_{3}=$ high $/$ good, $\mathrm{a}_{4}=$ very high $/$ good $\}$,

$S^{7}=\left\{b_{0}=\right.$ very low $/$ poor, $b_{1}=$ low $/$ poor, $b_{2}=$ moderately low/poor, $b_{3}=$ fair, $b_{4}=$ moderately high $/$ good, $\mathrm{b}_{5}=$ high/good, $\mathrm{b}_{6}=$ very high/good $\}$.

Interval 2-tuple linguistic evaluations on the alternative performances furnished by the three DMs are shown in Table 2. In addition, by Eq. (10), the individual performance evaluations of multi-alternative combinations are obtained, as displayed in Table 3.

(2) Collaborative performance evaluations

The performances of each pair of alternatives regarding collaborative criteria are appraised by the associated DMs with chosen linguistic term sets. To save space, the results in the form of interval 2-tuples are listed in Table A1. Based on Eqs. (11-13), the collaborative performance evaluations of alternative pairs and multi-alternative combinations are obtained, as shown in Tables 4 and 5, respectively.

Stage 2: Determine criteria weights using the ITL-BWM

The three DMs determine the most important and the least important individual criteria from their own viewpoints. Then, they choose suitable linguistic term sets from multi-granularity sets to evaluate the preference degrees of the most important individual criterion over others and other individual criteria over the least important individual criterion using interval linguistic variables. Specifically, $D M_{1}$ and $D M_{3}$ select linguistic term set $\bar{S}^{5}$, and $D M_{2}$ chooses linguistic term set $\bar{S}^{7}$. The linguistic term sets are displayed as follows:

$\bar{S}^{5}=\left\{\mathrm{c}_{0}=\right.$ equally important, $\mathrm{c}_{1}=$ moderately important, $\mathrm{c}_{2}=$ important, $\mathrm{c}_{3}=$ strongly important, $\mathrm{c}_{4}=$ absolutely important $\}$,

$\bar{S}^{7}=\left\{\mathrm{d}_{0}=\right.$ equally important, $\mathrm{d}_{1}=$ slightly important, $d_{2}=$ moderately important, $d_{3}=$ important, $d_{4}=$ strongly important, $\mathrm{d}_{5}=$ very strongly important, $\mathrm{d}_{6}=$ absolutely important\}.

According to the DMs' assessments, the ITLBO and ITLOW vectors on individual criteria are obtained, as listed in Table 6.

Based on model (15), the optimization model for individual criteria weights is built as follows:
Table 6 ITLBO and ITLOW vectors regarding individual criteria

\begin{tabular}{llllll}
\hline Decision maker & $\begin{array}{l}\text { Most/least important } \\
\text { individual criterion }\end{array}$ & & \multicolumn{4}{l}{ ITLBO/ITLOW vector } \\
\cline { 3 - 6 } & Most important: $I C_{2}$ & $A_{B}^{1}$ & {$\left[\left(\mathrm{c}_{2}, 0\right),\left(\mathrm{c}_{3}, 0\right)\right]$} & {$\left[\left(\mathrm{c}_{0}, 0\right),\left(\mathrm{c}_{0}, 0\right)\right]$} & {$\left[\left(\mathrm{c}_{1}, 0\right),\left(\mathrm{c}_{2}, 0\right)\right]$} \\
\hline$D M_{1}$ & Least important: $I C_{1}$ & $A_{W}^{1}$ & {$\left[\left(\mathrm{c}_{0}, 0\right),\left(\mathrm{c}_{0}, 0\right)\right]$} & {$\left[\left(\mathrm{c}_{3}, 0\right),\left(\mathrm{c}_{3}, 0\right)\right]$} & {$\left[\left(\mathrm{c}_{2}, 0\right),\left(\mathrm{c}_{3}, 0\right)\right]$} \\
& Most important: $I C_{1}$ & $A_{B}^{2}$ & {$\left[\left(\mathrm{~d}_{0}, 0\right),\left(\mathrm{d}_{0}, 0\right)\right]$} & {$\left[\left(\mathrm{d}_{1}, 0\right),\left(\mathrm{d}_{2}, 0\right)\right]$} & {$\left[\left(\mathrm{d}_{1}, 0\right),\left(\mathrm{d}_{1}, 0\right)\right]$} \\
$D M_{2}$ & Least important: $I C_{2}$ & $A_{W}^{2}$ & {$\left[\left(\mathrm{~d}_{2}, 0\right),\left(\mathrm{d}_{4}, 0\right)\right]$} & {$\left[\left(\mathrm{d}_{0}, 0\right),\left(\mathrm{d}_{0}, 0\right)\right]$} & {$\left[\left(\mathrm{d}_{1}, 0\right),\left(\mathrm{d}_{1}, 0\right)\right]$} \\
& Most important: $I C_{3}$ & $A_{B}^{3}$ & {$\left[\left(\mathrm{c}_{3}, 0\right),\left(\mathrm{c}_{4}, 0\right)\right]$} & {$\left[\left(\mathrm{c}_{1}, 0\right),\left(\mathrm{c}_{1}, 0\right)\right]$} & {$\left[\left(\mathrm{c}_{0}, 0\right),\left(\mathrm{c}_{0}, 0\right)\right]$} \\
$D M_{3}$ & Least important: $I C_{1}$ & $A_{W}^{3}$ & {$\left[\left(\mathrm{c}_{0}, 0\right),\left(\mathrm{c}_{0}, 0\right)\right]$} & {$\left[\left(\mathrm{c}_{1}, 0\right),\left(\mathrm{c}_{2}, 0\right)\right]$} & {$\left[\left(\mathrm{c}_{3}, 0\right),\left(\mathrm{c}_{4}, 0\right)\right]$} \\
\hline
\end{tabular}




$$
\begin{aligned}
& \min Z=0.3 \varepsilon_{1}^{*}+0.35 \varepsilon_{2}^{*}+0.35 \varepsilon_{3}^{*} \\
& s . t\left\{\begin{array}{l}
\left|\left[l_{2}^{w}, u_{2}^{w}\right]-\left[3^{\Delta^{-1}(c 2,0)} \cdot u_{1}^{w}, 3^{\Delta^{-1}(c 3,0)} \cdot l_{1}^{w}\right]\right| \leq\left[\chi_{1}^{*}, \chi_{1}^{*}\right],\left|\left[l_{2}^{w}, u_{2}^{w}\right]-\left[3^{\Delta^{-1}(c 0,0)} \cdot u_{2}^{w}, 3^{\Delta^{-1}(c 0,0)} \cdot l_{2}^{w}\right]\right| \leq\left[\chi_{1}^{*}, \chi_{1}^{*}\right] \\
\left|\left[l_{2}^{w}, u_{2}^{w}\right]-\left[3^{\Delta^{-1}(c 1,0)} \cdot u_{3}^{w}, 3^{\Delta^{-1}(c 2,0)} \cdot l_{3}^{w}\right]\right| \leq\left[\chi_{1}^{*}, \chi_{1}^{*}\right],\left|\left[l_{1}^{w}, u_{1}^{w}\right]-\left[3^{\Delta^{-1}(c 0,0)} \cdot u_{1}^{w}, 3^{\Delta^{-1}(c 0,0)} \cdot l_{1}^{w}\right]\right| \leq\left[\chi_{1}^{*}, \chi_{1}^{*}\right] \\
\left|\left[l_{2}^{w}, u_{2}^{w}\right]-\left[3^{\Delta^{-1}(c 3,0)} \cdot u_{1}^{w}, 3^{\Delta^{-1}(c 3,0)} \cdot l_{1}^{w}\right]\right| \leq\left[\chi_{1}^{*}, \chi_{1}^{*}\right],\left|\left[l_{3}^{w}, u_{3}^{w}\right]-\left[3^{\Delta^{-1}(c 2,0)} \cdot u_{1}^{w}, 3^{\Delta^{-1}(c 3,0)} \cdot l_{1}^{w}\right]\right| \leq\left[\chi_{1}^{*}, \chi_{1}^{*}\right] \\
\left|\left[l_{1}^{w}, u_{1}^{w}\right]-\left[4^{\Delta^{-1}(d 0,0)} \cdot u_{1}^{w}, 4^{\Delta^{-1}(d 0,0)} \cdot l_{1}^{w}\right]\right| \leq\left[\chi_{2}^{*}, \chi_{2}^{*}\right],\left|\left[l_{1}^{w}, u_{1}^{w}\right]-\left[4^{\Delta^{-1}(d 1,0)} \cdot u_{2}^{w}, 4^{\Delta^{-1}(d 2,0)} \cdot l_{2}^{w}\right]\right| \leq\left[\chi_{2}^{*}, \chi_{2}^{*}\right] \\
\left|\left[l_{1}^{w}, u_{1}^{w}\right]-\left[4^{\Delta^{-1}(d 1,0)} \cdot u_{3}^{w}, 4^{\Delta^{-1}(d 1,0)} \cdot l_{3}^{w}\right]\right| \leq\left[\chi_{2}^{*}, \chi_{2}^{*}\right],\left|\left[l_{1}^{w}, u_{1}^{w}\right]-\left[4^{\Delta^{-1}(d 2,0)} \cdot u_{2}^{w}, 4^{\Delta^{-1}(d 4,0)} \cdot l_{2}^{w}\right]\right| \leq\left[\chi_{2}^{*}, \chi_{2}^{*}\right] \\
\left|\left[l_{2}^{w}, u_{2}^{w}\right]-\left[4^{\Delta^{-1}(d 0,0)} \cdot u_{2}^{w}, 4^{\Delta^{-1}(d 0,0)} \cdot l_{2}^{w}\right]\right| \leq\left[\chi_{2}^{*}, \chi_{2}^{*}\right],\left|\left[l_{3}^{w}, u_{3}^{w}\right]-\left[4^{\Delta^{-1}(d 1,0)} \cdot u_{2}^{w}, 4^{\Delta^{-1}(d 1,0)} \cdot l_{2}^{w}\right]\right| \leq\left[\chi_{2}^{*}, \chi_{2}^{*}\right] \\
{\left[l_{3}^{w}, u_{3}^{w}\right]-\left[4^{\Delta^{-1}(c 3,0)} \cdot u_{1}^{w}, 4^{\Delta^{-1}(c 4,0)} \cdot l_{1}^{w}\right]\left|\leq\left[\chi_{3}^{*}, \chi_{3}^{*}\right],\right|\left[l_{3}^{w}, u_{3}^{w}\right]-\left[4^{\Delta^{-1}(c 1,0)} \cdot u_{2}^{w}, 4^{\Delta^{-1}(c 1,0)} \cdot l_{2}^{w}\right] \mid \leq\left[\chi_{3}^{*}, \chi_{3}^{*}\right]} \\
\left|\left[l_{3}^{w}, u_{3}^{w}\right]-\left[4^{\Delta^{-1}(c 0,0)} \cdot u_{3}^{w}, 4^{\Delta^{-1}(c 0,0)} \cdot l_{3}^{w}\right]\right| \leq\left[\chi_{3}^{*}, \chi_{3}^{*}\right],\left|\left[l_{1}^{w}, u_{1}^{w}\right]-\left[4^{\Delta^{-1}(c 0,0)} \cdot u_{1}^{w}, 4^{\Delta^{-1}(c 0,0)} \cdot l_{1}^{w}\right]\right| \leq\left[\chi_{3}^{*}, \chi_{3}^{*}\right] \\
\left|\left[l_{2}^{w}, u_{2}^{w}\right]-\left[4^{\Delta^{-1}(c 1,0)} \cdot u_{1}^{w}, 4^{\Delta^{-1}(c 2,0)} \cdot l_{1}^{w}\right]\right| \leq\left[\chi_{3}^{*}, \chi_{3}^{*}\right],\left|\left[l_{3}^{w}, u_{3}^{w}\right]-\left[4^{\Delta^{-1}(c 3,0)} \cdot u_{1}^{w}, 4^{\Delta^{-1}(c 4,0)} \cdot l_{1}^{w}\right]\right| \leq\left[\chi_{3}^{*}, \chi_{3}^{*}\right] \\
\sum_{9}^{3} u_{\vartheta}^{w}+l_{n}^{w} \geq 1, \sum_{\vartheta=1, \vartheta \neq n}^{3} l_{\vartheta}^{w}+u_{n}^{w} \leq 1 \\
\vartheta=1,9 \neq n \\
0 \leq l_{n}^{w} \leq u_{n}^{w} \\
n=1,2,3
\end{array}\right.
\end{aligned}
$$

By solving above model, $Z$ is obtained as 0.2958 , with $\varepsilon_{1}^{*}=0.2981, \varepsilon_{2}^{*}=0.4779$ and $\varepsilon_{3}^{*}=0.1118$. Additionally, the optimal interval weights of three individual criteria are calculated as $\bar{w}_{1}^{*}=[0.1043,0.2414], \bar{w}_{2}^{*}=[0.2310,0.4531]$ and $\bar{w}_{3}^{*}=[0.3055,0.5708]$. Then, the optimal weights of three individual criteria are derived via Eq. (16) as $w_{1}^{*}=0.1814$, $w_{2}^{*}=0.3589$ and $w_{3}^{*}=0.4597$.

Similarly, the preference degrees among collaborative criteria are assessed by the DMs, which are given in
Table A2. Then, based on model (15) and Eq. (16), the weight vector of collaborative criteria is determined as $(0.4671,0.2365,0.2964)$.

\section{Stage 3: Derive the priority ranking using the} ITL-TODIM

Based on the individual performance evaluations, the gain and loss matrices about individual criteria are obtained using Eqs. (17-22), i.e.,

$\hat{g}^{I C_{1}}=\left(\begin{array}{ccccccccc}0.0194 & 0.1314 & 0.0583 & 0.1896 & 0.1130 & 0.2438 & 0.1709 & 0.3021 \\ 0.0002 & 0.0340 & 0.0021 & 0.0062 & 0.0245 & 0.1188 & 0.0107 & 0.1709 \\ 0 & 0.0750 & 0 & 0.1313 & 0.0587 & 0.1854 & 0.1125 & 0.2438 \\ 0 & 0.0646 & 0 & 0.0146 & 0.1011 & 0.0684 & 0.0254 & 0.1125 \\ 0.0005 & 0.0433 & 0.0045 & 0.0240 & 0.0319 & 0.1348 & 0.0632 & 0.1896 \\ 0 & 0.0063 & 0 & 0.0142 & 0.0035 & 0.0465 & 0.0088 & 0.0741 \\ 0 & 0.0503 & 0 & 0.0066 & 0.0049 & 0.0817 & 0.0125 & 0.1312 \\ 0 & 0 & 0 & 0 & 0 & 0.0158 & 0 & 0.0271\end{array}\right)$,

$\hat{g}^{I C_{2}}=\left(\begin{array}{cccccccc}0.0243 & 0.0039 & 0.0052 & 0 & 0.1143 & 0.0718 & 0.0653 & 0.0018 \\ 0.0476 & 0.0097 & 0.0126 & 0 & 0.1563 & 0.1125 & 0.0988 & 0.0557 \\ 0.0636 & 0.0272 & 0.0243 & 0.0039 & 0.1709 & 0.1271 & 0.1143 & 0.0718 \\ 0.1021 & 0.0584 & 0.0476 & 0.0097 & 0.2146 & 0.1709 & 0.1563 & 0.1125 \\ 0.0018 & 0 & 0 & 0 & 0.0368 & 0.0134 & 0.0147 & 0.0024 \\ 0.0031 & 0 & 0 & 0 & 0.0572 & 0.0222 & 0.0241 & 0.0040 \\ 0.0112 & 0.0009 & 0.0018 & 0 & 0.0730 & 0.0387 & 0.0368 & 0.0134 \\ 0.1143 & 0.0016 & 0.0030 & 0 & 0.1045 & 0.0623 & 0.0572 & 0.0222\end{array}\right)$, 


$$
\begin{aligned}
& \hat{g}^{I C_{3}}=\left(\begin{array}{ccccccccc}
0.0444 & 0.1414 & 0.0563 & 0.1641 & 0.0085 & 0.0739 & 0.0149 & 0.0930 \\
0.0102 & 0.0590 & 0.0130 & 0.0703 & 0.0001 & 0.0196 & 0.0002 & 0.0268 \\
0.0271 & 0.1151 & 0.0347 & 0.1360 & 0.0014 & 0.0496 & 0.0027 & 0.0659 \\
0.0037 & 0.0412 & 0.0048 & 0.0493 & 0 & 0.0086 & 0 & 0.0120 \\
0.0835 & 0.2064 & 0.1055 & 0.2354 & 0.0195 & 0.1314 & 0.0340 & 0.1604 \\
0.0176 & 0.0946 & 0.0225 & 0.1127 & 0.0002 & 0.0340 & 0.0003 & 0.0465 \\
0.0607 & 0.1773 & 0.0777 & 0.2063 & 0.0049 & 0.1024 & 0.0097 & 0.1312 \\
0.0076 & 0.0727 & 0.0097 & 0.0870 & 0 & 0.0174 & 0 & 0.0243
\end{array}\right), \\
& \hat{l}^{I C_{1}}=\left(\begin{array}{cccccccc}
-0.0194 & -0.0002 & 0 & 0 & -0.0005 & 0 & 0 & 0 \\
-0.1314 & -0.0340 & -0.0750 & -0.0646 & -0.0433 & -0.0063 & -0.0503 & 0 \\
-0.0583 & -0.0021 & 0 & 0 & -0.0045 & 0 & 0 & 0 \\
-0.1896 & -0.0062 & -0.1313 & -0.0146 & -0.0240 & -0.0142 & -0.0066 & 0 \\
-0.1130 & -0.0245 & -0.0587 & -0.1011 & -0.0319 & -0.0035 & -0.0049 & 0 \\
-0.2438 & -0.1188 & -0.1854 & -0.0684 & -0.1348 & -0.0465 & -0.0817 & -0.0158 \\
-0.1709 & -0.0107 & -0.1125 & -0.0254 & -0.0632 & -0.0088 & -0.0125 & 0 \\
-0.3021 & -0.1709 & -0.2438 & -0.1125 & -0.1896 & -0.0741 & -0.1312 & -0.0271
\end{array}\right) \text {, } \\
& \hat{l}^{I C_{2}}=\left(\begin{array}{cccccccc}
-0.0243 & -0.0476 & -0.0636 & -0.1021 & -0.0018 & -0.0031 & -0.0112 & -0.1143 \\
-0.0039 & -0.0097 & -0.0272 & -0.0584 & 0 & 0 & -0.0009 & -0.0016 \\
-0.0052 & -0.0126 & -0.0243 & -0.0476 & 0 & 0 & -0.0018 & -0.0030 \\
0 & 0 & -0.0039 & -0.0097 & 0 & 0 & 0 & 0 \\
-0.1143 & -0.1563 & -0.1709 & -0.2146 & -0.0368 & -0.0572 & -0.0730 & -0.1045 \\
-0.0718 & -0.1125 & -0.1271 & -0.1709 & -0.0134 & -0.0222 & -0.0387 & -0.0623 \\
-0.0653 & -0.0988 & -0.1143 & -0.1563 & -0.0147 & -0.0241 & -0.0368 & -0.0572 \\
-0.0018 & -0.0557 & -0.0718 & -0.1125 & -0.0024 & -0.0040 & -0.0134 & -0.0222
\end{array}\right),
\end{aligned}
$$

$$
\hat{l}^{I C_{3}}=\left(\begin{array}{cccccccc}
-0.0444 & -0.0102 & -0.0271 & -0.0037 & -0.0835 & -0.0176 & -0.0607 & -0.0076 \\
-0.1414 & -0.0590 & -0.1151 & -0.0412 & -0.2064 & -0.0946 & -0.1773 & -0.0727 \\
-0.0563 & -0.0130 & -0.0347 & -0.0048 & -0.1055 & -0.0225 & -0.0777 & -0.0097 \\
-0.1641 & -0.0703 & -0.1360 & -0.0493 & -0.2354 & -0.1127 & -0.2063 & -0.0870 \\
-0.0085 & -0.0001 & -0.0014 & 0 & -0.0195 & -0.0002 & -0.0049 & 0 \\
-0.0739 & -0.0196 & -0.0496 & -0.0086 & -0.1314 & -0.0340 & -0.1024 & -0.0174 \\
-0.0149 & -0.0002 & -0.0027 & 0 & -0.0340 & -0.0003 & -0.0097 & 0 \\
-0.0930 & -0.0268 & -0.0659 & -0.0120 & -0.1604 & -0.0465 & -0.1312 & -0.0243
\end{array}\right) .
$$

After normalization of the gain and loss matrices by Eqs. $(23,24)$, the positive and negative dominance degrees among multi-alternative combinations concerning individual criteria are computed through Eqs. $(25,26)$, where the attenuation factor $\theta$ is considered to be 1 in this paper, i.e.,

$$
\psi^{I C_{1}+}=\left(\begin{array}{cccccccc}
0.1079 & 0.2809 & 0.1871 & 0.3374 & 0.2605 & 0.3826 & 0.3203 & 0.4259 \\
0.0110 & 0.1429 & 0.0355 & 0.0610 & 0.1213 & 0.2671 & 0.0802 & 0.3203 \\
0 & 0.2122 & 0 & 0.2808 & 0.1877 & 0.3337 & 0.2599 & 0.3826 \\
0 & 0.1970 & 0 & 0.0936 & 0.2464 & 0.2027 & 0.1235 & 0.2599 \\
0.0173 & 0.1612 & 0.0520 & 0.1200 & 0.1384 & 0.2845 & 0.1948 & 0.3374 \\
0 & 0.0615 & 0 & 0.0923 & 0.0458 & 0.1671 & 0.0727 & 0.2109 \\
0 & 0.1738 & 0 & 0.0630 & 0.0542 & 0.2215 & 0.0866 & 0.2807 \\
0 & 0 & 0 & 0 & 0 & 0.0974 & 0 & 0.1276
\end{array}\right),
$$


Table 7 Dominance values and solution ranking

\begin{tabular}{lllll}
\hline $\begin{array}{l}\text { Multi-alternative combi- } \\
\text { nations }\end{array}$ & $\begin{array}{l}\text { Dominance values } \\
\xi^{I C}\left(A_{n_{D_{1}}}^{D_{1}} A_{n_{D_{2}}}^{D_{2}} \cdots A_{n_{D_{J}}}^{D_{J}}\right)\end{array}$ & $\xi^{C C}\left(A_{n_{D_{1}}}^{D_{1_{1}}} A_{n_{D_{2}}}^{D_{2}} \cdots A_{n_{D_{J}}}^{D_{J}}\right)$ & $\xi\left(A_{n_{D_{1}}}^{D_{1}} A_{n_{D_{2}}}^{D_{2}} \cdots A_{n_{D_{J}}}^{D_{J}}\right)$ & $\begin{array}{l}\text { Solution } \\
\text { ranking }\end{array}$ \\
\hline$A_{1}^{D_{1}} A_{1}^{D_{2}} A_{1}^{D_{3}}$ & 0.9133 & 0 & 0.4567 & 6 \\
$A_{1}^{D_{1}} A_{1}^{D_{2}} A_{2}^{D_{3}}$ & 0.4269 & 0.3772 & 0.4020 & 8 \\
$A_{1}^{D_{1}} A_{2}^{D_{2}} A_{1}^{D_{3}}$ & 1 & 0.1866 & 0.5933 & 2 \\
$A_{1}^{D_{1}} A_{2}^{D_{2}} A_{2}^{D_{3}}$ & 0.5757 & 0.5338 & 0.5548 & 4 \\
$A_{2}^{D_{1}} A_{1}^{D_{2}} A_{1}^{D_{3}}$ & 0.5118 & 0.6488 & 0.5803 & 3 \\
$A_{2}^{D_{1}} A_{1}^{D_{2}} A_{2}^{D_{3}}$ & 0 & 0.8886 & 0.4443 & 7 \\
$A_{2}^{D_{1}} A_{2}^{D_{2}} A_{1}^{D_{3}}$ & 0.5661 & 0.8309 & 0.6985 & 1 \\
$A_{2}^{D_{1}} A_{2}^{D_{2}} A_{2}^{D_{3}}$ & 0.0091 & 1 & 0.5045 & 5 \\
\hline
\end{tabular}

$\psi^{I C_{2}+}=\left(\begin{array}{ccccccccc}0.2016 & 0.0808 & 0.0933 & 0 & 0.4372 & 0.3465 & 0.3305 & 0.0549 \\ 0.2821 & 0.1274 & 0.1452 & 0 & 0.5113 & 0.4338 & 0.4065 & 0.3052 \\ 0.3261 & 0.2133 & 0.2016 & 0.0808 & 0.5346 & 0.4610 & 0.4372 & 0.3465 \\ 0.4132 & 0.3125 & 0.2821 & 0.1274 & 0.5991 & 0.5346 & 0.5113 & 0.4338 \\ 0.0549 & 0 & 0 & 0 & 0.2481 & 0.1497 & 0.1568 & 0.0634 \\ 0.0720 & 0 & 0 & 0 & 0.3093 & 0.1927 & 0.2008 & 0.0818 \\ 0.1369 & 0.0388 & 0.0549 & 0 & 0.3494 & 0.2544 & 0.2481 & 0.1497 \\ 0.4372 & 0.0517 & 0.0708 & 0 & 0.4181 & 0.3228 & 0.3093 & 0.1927\end{array}\right)$,

$\psi^{I C_{3}+}=\left(\begin{array}{ccccccccc}0.2945 & 0.5255 & 0.3316 & 0.5661 & 0.1288 & 0.3799 & 0.1706 & 0.4262 \\ 0.1411 & 0.3394 & 0.1593 & 0.3705 & 0.0140 & 0.1956 & 0.0198 & 0.2288 \\ 0.2300 & 0.4741 & 0.2603 & 0.5154 & 0.0523 & 0.3112 & 0.0726 & 0.3587 \\ 0.0850 & 0.2836 & 0.0968 & 0.3103 & 0 & 0.1296 & 0 & 0.1531 \\ 0.4038 & 0.6349 & 0.4539 & 0.6780 & 0.1951 & 0.5066 & 0.2577 & 0.5597 \\ 0.1854 & 0.4298 & 0.2096 & 0.4691 & 0.0198 & 0.2577 & 0.0242 & 0.3013 \\ 0.3443 & 0.5884 & 0.3895 & 0.6347 & 0.0978 & 0.4472 & 0.1376 & 0.5062 \\ 0.1218 & 0.3768 & 0.1376 & 0.4122 & 0 & 0.1843 & 0 & 0.2178\end{array}\right)$,

$\psi^{I C_{1}-}=\left(\begin{array}{cccccccc}-0.5950 & -0.0604 & 0 & 0 & -0.0955 & 0 & 0 & 0 \\ -1.5485 & -0.7877 & -1.1699 & -1.0858 & -0.8889 & -0.3391 & -0.9581 & 0 \\ -1.0315 & -0.1958 & 0 & 0 & -0.2866 & 0 & 0 & 0 \\ -1.8601 & -0.3364 & -1.5479 & -0.5162 & -0.6618 & -0.5091 & -0.3470 & 0 \\ -1.4360 & -0.6687 & -1.0350 & -1.3583 & -0.7630 & -0.2527 & -0.2990 & 0 \\ -2.1093 & -1.4724 & -1.8394 & -1.1172 & -1.5684 & -0.9212 & -1.2210 & -0.5370 \\ -1.7660 & -0.4419 & -1.4328 & -0.6808 & -1.0739 & -0.4007 & -0.4776 & 0 \\ -2.3480 & -1.7660 & -2.1093 & -1.4328 & -1.8601 & -1.1629 & -1.5473 & -0.7032\end{array}\right)$, 
Table 8 Ranking results for different $\sigma$

\begin{tabular}{lll}
\hline$\sigma$ & Ranking & Best solution \\
\hline 0 & $M A C_{3}>M A C_{1}>M A C_{4}>M A C_{7}>M A C_{5}>M A C_{2}>M A C_{8}>M A C_{6}$ & $M A C_{3}$ \\
0.1 & $M A C_{3}>M A C_{1}>M A C_{7}>M A C_{4}>M A C_{5}>M A C_{2}>M A C_{8}>M A C_{6}$ & $M A C_{3}$ \\
0.2 & $M A C_{3}>M A C_{1}>M A C_{7}>M A C_{4}>M A C_{5}>M A C_{2}>M A C_{8}>M A C_{6}$ & $M A C_{3}$ \\
0.3 & $M A C_{3}>M A C_{7}>M A C_{1}>M A C_{4}>M A C_{5}>M A C_{2}>M A C_{8}>M A C_{6}$ & $M A C_{3}$ \\
0.4 & $M A C_{3}>M A C_{7}>M A C_{5}>M A C_{4}>M A C_{1}>M A C_{2}>M A C_{8}>M A C_{6}$ & $M A C_{3}$ \\
0.5 & $M A C_{7}>M A C_{3}>M A C_{5}>M A C_{4}>M A C_{8}>M A C_{1}>M A C_{6}>M A C_{2}$ & $M A C_{7}$ \\
0.6 & $M A C_{7}>M A C_{8}>M A C_{5}>M A C_{4}>M A C_{6}>M A C_{3}>M A C_{2}>M A C_{1}$ & $M A C_{7}$ \\
0.7 & $M A C_{7}>M A C_{8}>M A C_{6}>M A C_{5}>M A C_{4}>M A C_{3}>M A C_{2}>M A C_{1}$ & $M A C_{7}$ \\
0.8 & $M A C_{8}>M A C_{7}>M A C_{6}>M A C_{5}>M A C_{4}>M A C_{2}>M A C_{3}>M A C_{1}$ & $M A C_{8}$ \\
0.9 & $M A C_{8}>M A C_{7}>M A C_{6}>M A C_{5}>M A C_{4}>M A C_{2}>M A C_{3}>M A C_{1}$ & $M A C_{8}$ \\
1 & $M A C_{8}>M A C_{6}>M A C_{7}>M A C_{5}>M A C_{4}>M A C_{2}>M A C_{3}>M A C_{1}$ & $M A C_{8}$ \\
\hline
\end{tabular}

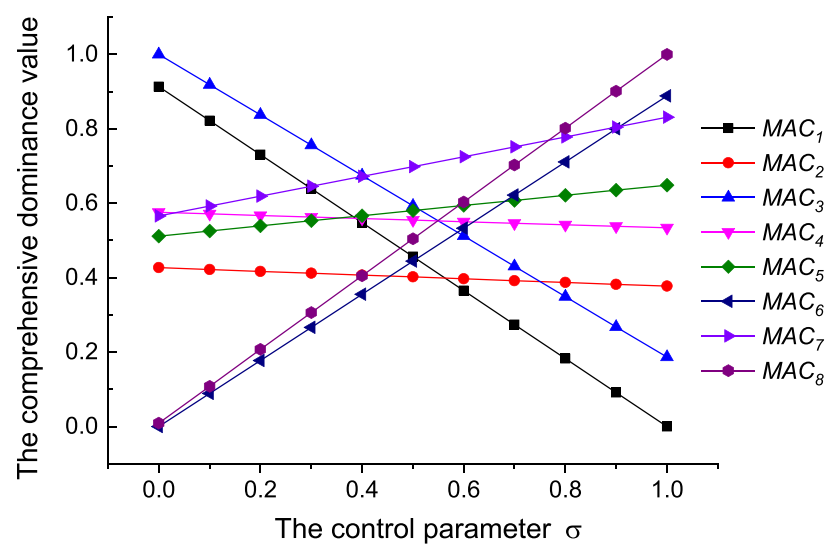

Fig. 2 The comprehensive dominance values under different values of $\sigma$

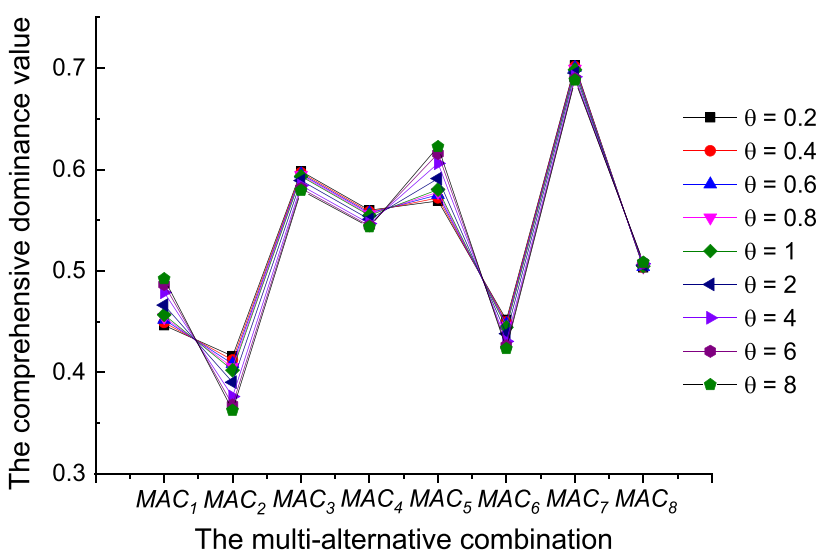

Fig. 3 The comprehensive dominance values under different $\theta$ values

$\psi^{I C_{2}-}=\left(\begin{array}{cccccccc}-0.5617 & -0.7861 & -0.9087 & -1.1514 & -0.1529 & -0.2006 & -0.3813 & -1.2182 \\ -0.2250 & -0.3549 & -0.5943 & -0.8708 & 0 & 0 & -0.1081 & -0.1441 \\ -0.2598 & -0.4045 & -0.5617 & -0.7861 & 0 & 0 & -0.1529 & -0.1974 \\ 0 & 0 & -0.2250 & -0.3549 & 0 & 0 & 0 & 0 \\ -1.2182 & -1.4246 & -1.4896 & -1.6692 & -0.6912 & -0.8618 & -0.9736 & -1.1648 \\ -0.9655 & -1.2086 & -1.2846 & -1.4896 & -0.4171 & -0.5369 & -0.7089 & -0.8994 \\ -0.9208 & -1.1326 & -1.2182 & -1.4246 & -0.4369 & -0.5594 & -0.6912 & -0.8618 \\ -0.1529 & -0.8504 & -0.9655 & -1.2086 & -0.1765 & -0.2279 & -0.4171 & -0.5369\end{array}\right)$,

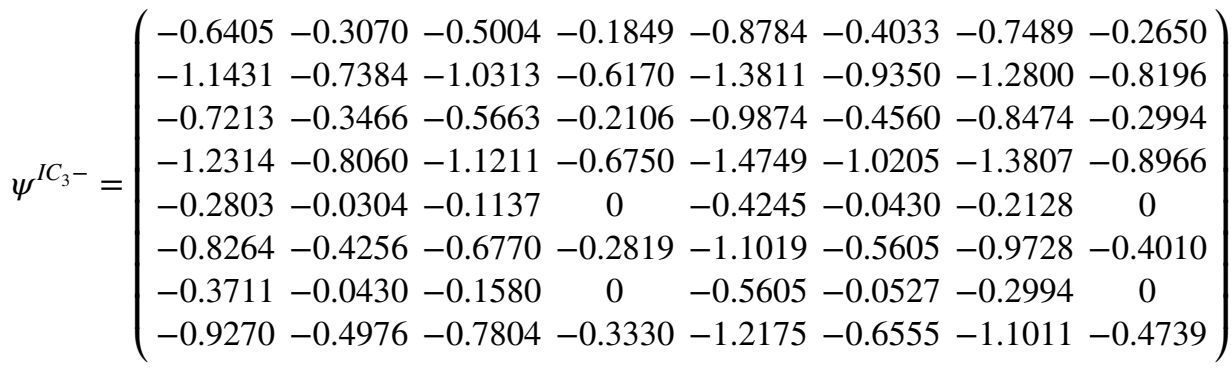


According to Eq. (27), the dominance degree matrix is constructed as follows:

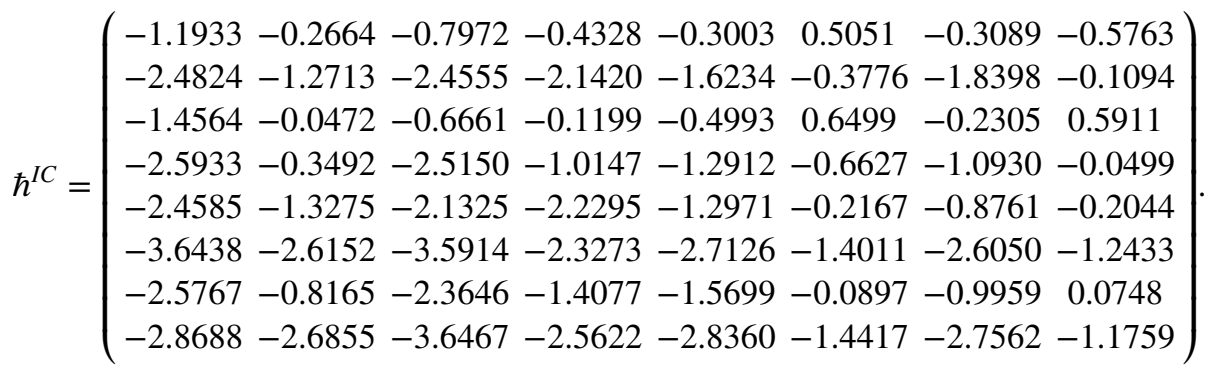

By Eq. (28), the overall dominance value $\xi^{I C}\left(A_{n_{D_{1}}}^{D_{1}} A_{n_{D_{2}}}^{D_{2}} \cdots A_{n_{D_{J}}}^{D_{J}}\right)$ with respect to individual criteria of each multi-alternative combination is obtained, as listed in Table 7.

In a similar manner, on the basis of collaborative performance evaluations, the overall dominance value $\xi^{C C}\left(A_{n_{D_{1}}}^{D_{1}} A_{n_{D_{2}}}^{D_{2}} \cdots A_{n_{D_{J}}}^{D_{J}}\right)$ with respect to the collaborative criteria of each multi-alternative combination can also be determined by using ITL-TODIM method. Then, the comprehensive dominance values $\xi\left(A_{n_{D_{1}}}^{D_{1}} A_{n_{D_{2}}}^{D_{2}} \cdots A_{n_{D_{J}}}^{D_{J}}\right)$ are calculated via Eq. (29), according to which the multi-alternative combinations are ranked. Here, without loss of generality, the control parameter $\sigma$ is set as 0.5 . Table 7 displays the above results.

It can be seen from Table 7 that the optimal multi-alternative combination for the response to the current landside accident is $A_{2}^{D_{1}} A_{2}^{D_{2}} A_{1}^{D_{3}}$. The worst multi-alternative combination is $A_{1}^{D_{1}} A_{1}^{D_{2}} A_{2}^{D_{3}}$, which is the reciprocal version of the optimal solution.

\section{Discussion}

In this section, a sensitivity analysis is provided to show the effect of different values of the control parameter $\sigma$ and loss attenuation factor $\theta$ on the solution ranking. Furthermore, a comparative analysis is carried out to demonstrate the validity of the proposed method.

\subsection{Sensitivity analysis}

(1) The effect of $\sigma$ on the solution ranking

In the above implementation process, the control parameter $\sigma$ is taken as 0.5 in calculating the comprehensive dominance values. However, if the synergy effect among different alternatives supplied by different emergency departments is considered more or less, i.e., $\sigma=1$ or $\sigma=0$, it is obvious that the comprehensive dominance value of each multi-alternative combination together with its ranking may be changed. The change trends of comprehensive dominance values over $\sigma$ are vividly shown in Fig. 2, where $\operatorname{MAC}_{i}(i=1,2, \ldots, 8)$ represents the multi-alternative combinations listed in the first column of Table 7 from top to bottom.

The ranking orders of multi-alternative combinations under different $\sigma$ values are displayed in Table 8. It can be observed that the solution rankings are changed with different values of $\sigma$. More specifically, for $\sigma$ from 0 to $0.4, M A C_{3}$ is the most desirable one. For $\sigma$ from 0.5 to $0.7, M A C_{7}$ is the most desirable one. For $\sigma$ from 0.8 to
Table 9 Ranking results for different $\theta$

\begin{tabular}{llc}
\hline$\theta$ & Ranking & Best solution \\
\hline $0.2,0.4$ & $M A C_{7}>M A C_{3}>M A C_{5}>M A C_{4}>M A C_{8}>M A C_{6}>M A C_{1}>M A C_{2}$ & $M A C_{7}$ \\
$0.6,0.8,1$ & $M A C_{7}>M A C_{3}>M A C_{5}>M A C_{4}>M A C_{8}>M A C_{1}>M A C_{6}>M A C_{2}$ & \\
$2,4,6,8$ & $M A C_{7}>M A C_{5}>M A C_{3}>M A C_{4}>M A C_{8}>M A C_{1}>M A C_{6}>M A C_{2}$ & \\
\hline
\end{tabular}

\begin{tabular}{lll}
\hline Method & Ranking & Best solution \\
\hline Proposed method & $M A C_{7}>M A C_{3}>M A C_{5}>M A C_{4}>M A C_{8}>M A C_{1}>M A C_{6}>M A C_{2}$ & $M A C_{7}$ \\
Method-I & $M A C_{7}>M A C_{5}>M A C_{3}>M A C_{8}>M A C_{1}>M A C_{4}>M A C_{6}>M A C_{2}$ & \\
Method-II & $M A C_{7}>M A C_{5}>M A C_{3}>M A C_{8}>M A C_{1}>M A C_{4}>M A C_{6}>M A C_{2}$ & \\
Method-III & $M A C_{7}>M A C_{8}>M A C_{5}>M A C_{6}>M A C_{4}>M A C_{3}>M A C_{2}>M A C_{1}$ & \\
\hline
\end{tabular}

Table 10 Ranking results obtained by different methods 
1, the most desirable one changes to $M A C_{8}$. Therefore, in the selection of a multi-alternative combination to deal with the emergency, considering the synergy effect between different alternatives indeed brings about different decision results, which demonstrates its necessity and rationality. In addition, DMs should choose a rational value of $\sigma$ to trade off the individual and collaborative performances according to the needs of realworld decision making situations.

(2) The effect of $\theta$ on the solution ranking

On account of the influence of the loss attenuation factor $\theta$ in Eq. (26), we use different values of $\theta$ to observe the change in ranking results. When $\theta>1$, the influence of loss is weakened. In contrast, when $0<\theta \leq 1$, the influence of loss is amplified. Thus, the value of $\theta$ is divided into two ranges: $0<\theta \leq 1$ and $\theta>1$. Figure 3 describes the comprehensive dominance values of multi-alternative combinations with different $\theta$ values. It can be seen that the trends of the comprehensive dominance values under different $\theta$ values are consistent. Although the comprehensive dominance values slightly change for different $\theta$ values, the largest ones are always associated with $M A C_{7}$.

Table 9 presents the solution rankings of multi-alternative combinations under different values of $\theta$. As can be observed, the best solution is always $M A C_{7}$. Nevertheless, taking a closer look, the ranking orders undergo some interchanges as $\theta$ increases. More specifically, the ranking order changes at $\theta=0.6$, with $M A C_{1}$ and $M A C_{6}$ being interchanged. This order stays the same until $\theta$ is equal to 1 . At $\theta=2$, the ranking order changes again, with $M A C_{3}$ and $M A C_{5}$ being interchanged. This order remains unchanged until $\theta$ is equal to 8 . Hence, although the final decision results are not sensitive to the change in $\theta$ values for the considered example, it is suggested that in a practical application, DMs should also select a reasonable value of $\theta$ to reflect their preferences about the influence of loss.

\subsection{Comparative analysis}

Regarding EDM problems, previous studies have mainly focused on how to select an optimal alternative from several alternatives. However, the decision making of multiple alternatives from multiple departments and the synergy among different department alternatives are rarely reported in the literature but are often encountered in real-world EDM situations. This study investigates a multi-criteria decision making method for determining the best multi-alternative combination composed of alternatives provided by different emergency departments, considering both the individual performance of each alternative and the collaborative performance between different department alternatives.
With the aid of the developed method, more realistic emergency decision results can be produced that support DMs in improving the emergency response performance. In the proposed approach, the construction procedure of individual and collaborative performance evaluations of multi-alternative combinations is first introduced, and then the extended BWM and TODIM methods with interval 2-tuple linguistic information are developed to find the most desirable multialternative combination.

To verify the effectiveness and superiority of the proposed method, a comparative analysis is conducted between the proposed method and three existing methods: the BWMTODIM method [14, 50], the BWM and multi-granularity interval 2-tuple linguistic TODIM [24], and the fuzzy BWM and fuzzy TOPSIS [44]. For concision, above three methods are denoted as Method-I, Method-II and Method-III, respectively. For a valid comparison, interval linguistic evaluation information used in the proposed method is converted into crisp numbers for implementing Method-I. The obtained crisp preferences on the relative importance of criteria are also used in Method-II. Additionally, the average values of interval linguistic evaluations are calculated and then transformed into triangular fuzzy numbers adopted in MethodIII. After these operations, above three methods are applied to solve the same EDM problem described in Sect. 5. The ranking results derived by these approaches are displayed in Table 10.

From Table 10, it can be seen that despite some differences in the ranking orders, the multi-alternative combination with the highest priority is still $M A C_{7}$. This finding validates the outcome obtained by the proposed method to some extent. To reflect the correlation between the ranking results of proposed method and three existing methods, the Spearman rank correlation coefficient is computed. It is observed that the correlation between the suggested method and Method-I is the same as that between the suggested method and Method-II, with a value of 0.9048. As recommended by Ghorabaee et al. [20], a Spearman rank correlation coefficient higher than 0.8 shows a remarkably high correlation. Though there are some ranking variations that may result from not fully addressing the vagueness and uncertainty of DMs' assessments in Method-I and MethodII. It can also be claimed that the ranking orders obtained by the proposed method, Method-I and Method-II have a considerable correlation. For the proposed method and MethodIII, the Spearman rank correlation coefficient between the ranking orders is determined to be 0.5238 , which indicates a lower correlation. The reasons for this may come from two aspects: criteria weight determination and ranking method.

About criteria weight determination, the crisp average weights of three individual criteria are $0.2344,0.3570$ and 0.4086 , as derived by the fuzzy BWM. These results show that there are some differences among each of the weights 
between the ITL-BWM and fuzzy BWM even when the preference orders of individual criteria are the same. For collaborative criteria, their crisp average weights obtained by the fuzzy BWM are 0.3918, 0.2080 and 0.4002 . It is obvious that the preference orders of collaborative criteria are different between the ITL-BWM and fuzzy BWM. Through the ITL-BWM, the preference order places $C C_{1}$ ahead of $C C_{3}$; however, the order is reversed by the fuzzy BWM. In fact, as shown in Table A2, $C C_{1}$ is considered the most important collaborative criterion by two DMs with larger weights, whereas $\mathrm{CC}_{3}$ is taken as the most important criterion by only one decision maker with a smaller weight and as the least important criterion by a decision maker with a larger weight. From this point of view, the preference order obtained by the proposed ITL-BWM is more reasonable. On the other hand, the different characteristics of the ranking methods used in the proposed method and Method-III may also cause the difference in ranking results. The fundamental of fuzzy TOPSIS is that the best solution should have the shortest distance from the positive ideal solution and the farthest distance from the negative ideal solution. In contrast, ITLTODIM method is based on the principle that the optimal solution should possess the greatest dominance over others determined by the gain and loss degrees of one solution relative to another. The latter takes the DMs' psychological behaviours into consideration and can reflect the DMs' bounded rationality, which is more veritable and reasonable.

To further demonstrate the advantages of the proposed method, closer comparisons are presented from the aspects of evaluation information modelling, criteria weight determination, and decision making and ranking.

In regard to evaluation information modelling, interval 2-tuple linguistic representation model is adopted to flexibly represent and accurately process the evaluation information expressed by DMs in the proposed method, which allows DMs to provide some imprecise and uncertain linguistic assessments from multi-granularity linguistic term sets. However, for example, Method-I and Method-II used crisp numbers to model the assessments supplied by DMs in the whole and partial decision procedures, respectively. Thus, the vagueness and uncertainty involved in the EDM are not addressed. In Method-III, DMs were restricted to provide evaluation information with only one linguistic term from the pre-defined linguistic term set, which cannot reflect the uncertainty and diversity of assessments. Moreover, linguistic assessments were converted into triangular fuzzy numbers, and the loss or distortion of information may occur, as pointed out by Wan et al. [59].

Regarding criteria weight determination, a new extension of BWM, namely, the ITL-BWM, on the basis of the interval preference degree and group decision making, is suggested to derive the criteria weights in this study. Each decision maker determines the best and worst criteria from his/her opinion and expresses the interval linguistic preference degrees. Then, an interval fuzzy mathematical programming model is established to incorporate the group decisions and produce a single set of weights. Nevertheless, group decision making is not considered in the three compared existing methods; thus, only one decision maker makes decisions, which is not enough to cope effectively with the decision problem. This is particularly true in EDM, which is fraught with complexity and uncertainty and usually requires multiple perspectives of different DMs.

For decision making and ranking, the ITL-TODIM method is proposed to rank the solutions in this paper that considers DMs' bounded cognition and psychological behaviours under interval linguistic information environment. However, the fuzzy TOPSIS used in Method-III fails to capture the DMs' psychological behaviours, which does not conform with the actual decision making under risk and uncertainty. In the ITL-TODIM method, both the gain and loss degrees of one solution relative to another are simultaneously computed. This is because the relationship between two interval 2-tuple linguistic evaluations causes difficulty in calculating the gain degree or loss degree. Therefore, to avoid information loss and inaccurate decisions, both the gain and loss degrees should be considered. However, the existing methods, such as the multi-granularity interval 2-tuple linguistic TODIM developed in Method-III, only computed the gain degree or loss degree individually.

Based on the above comparative analysis, the advantages of the proposed method for addressing the collaborative emergency decision making problem in this study are as follows:

(1) The proposed method offers a natural and flexible manner for DMs to express their evaluation information within the interval 2-tuple linguistic environment, by which the assessments can be precisely processed and the diversity and uncertainty of the assessments can be well reflected and modelled.

(2) The developed ITL-BWM considers group decision making, which can more effectively deal with the emergency decision making problem and has wider applicability in decision making.

(3) The suggested method takes into account DMs' psychological behaviours under risk and uncertainty, which can better reflect DMs' way of thinking in practical decision making situations. Besides, the proposed ITLTODIM method simultaneously calculates the gain and loss degrees that can avoid information loss and produce more accurate ranking results. 


\section{Conclusions}

Due to the urgency and complexity of emergencies, emergency response usually requires the participation of multiple emergency departments. In this study, a CEDM approach considering the synergy between different department alternatives is proposed based on the BWM and TODIM methods with interval 2-tuple linguistic information. To select the optimal solution to an emergency response, both the individual performance of each alternative and the collaborative performance between different department alternatives are considered, which is helpful in obtaining more practical emergency decision results. The proposed approach represents DMs' assessments by virtue of interval 2-tuple linguistic model, and diversified and uncertain linguistic evaluations can be well captured and exactly processed. The developed ITL-BWM offers a simple and reliable way to determine the weights of criteria and has a wider range of applications in group decision making. Additionally, with the suggested ITL-TODIM method, the bounded rationality of DMs in risky and uncertain EDM processes is considered, and both the gain and loss degrees are calculated, which enables more practical and accurate decision results.
A numerical example of a landslide accident rescue is given to demonstrate the effectiveness and practicability of the proposed CEDM approach. It was shown that the suggested method is a useful tool for flexibly modelling ambiguous and uncertain assessment information and finding the best emergency rescue solution in dealing with CEDM issues.

Future studies will focus on the following aspects. First, only the DMs of departments involved in emergency disposal are considered. However, in the real world, senior DMs from superior departments often participate in and lead a decision group to ensure appropriate decision results. Thus, a significant future work is to incorporate the participation of senior DMs into the proposed method. Second, the current approach is static; in the future, it will be modified to achieve a dynamic approach to determine the best solution with the evolution of emergency events. Finally, for the convenience of practical application and fast decision making in emergency situations, a computer-based decision support system will be developed based on the proposed method.

\section{Appendix A}

See Tables A1 and A2.
Table A1 Interval 2-tuple linguistic evaluations on the performances of alternative pairs regarding collaborative criteria

\begin{tabular}{|c|c|c|c|c|}
\hline \multirow[t]{2}{*}{ Pair of alternatives } & \multirow[t]{2}{*}{ Decision maker } & \multicolumn{3}{|c|}{ Collaborative criteria } \\
\hline & & $C C_{1}$ & $C C_{2}$ & $C C_{3}$ \\
\hline \multirow[t]{2}{*}{$\left(A_{1}^{D_{1}}, A_{1}^{D_{2}}\right)$} & $D M_{1}$ & {$\left[\left(\mathrm{a}_{1}, 0\right),\left(\mathrm{a}_{2}, 0\right)\right]$} & {$\left[\left(\mathrm{a}_{2}, 0\right),\left(\mathrm{a}_{2}, 0\right)\right]$} & {$\left[\left(\mathrm{a}_{1}, 0\right),\left(\mathrm{a}_{2}, 0\right)\right]$} \\
\hline & $D M_{2}$ & {$\left[\left(b_{3}, 0\right),\left(b_{3}, 0\right)\right]$} & {$\left[\left(b_{3}, 0\right),\left(b_{4}, 0\right)\right]$} & {$\left[\left(\mathrm{b}_{1}, 0\right),\left(\mathrm{b}_{3}, 0\right)\right]$} \\
\hline \multirow[t]{2}{*}{$\left(A_{1}^{D_{1}}, A_{2}^{D_{2}}\right)$} & $D M_{1}$ & {$\left[\left(\mathrm{a}_{2}, 0\right),\left(\mathrm{a}_{3}, 0\right)\right]$} & {$\left[\left(\mathrm{a}_{3}, 0\right),\left(\mathrm{a}_{3}, 0\right)\right]$} & {$\left[\left(a_{2}, 0\right),\left(a_{2}, 0\right)\right]$} \\
\hline & $D M_{2}$ & {$\left[\left(b_{3}, 0\right),\left(b_{4}, 0\right)\right]$} & {$\left[\left(b_{3}, 0\right),\left(b_{5}, 0\right)\right]$} & {$\left[\left(b_{3}, 0\right),\left(b_{3}, 0\right)\right]$} \\
\hline \multirow[t]{2}{*}{$\left(A_{1}^{D_{1}}, A_{1}^{D_{3}}\right)$} & $D M_{1}$ & {$\left[\left(\mathrm{a}_{0}, 0\right),\left(\mathrm{a}_{0}, 0\right)\right]$} & {$\left[\left(\mathrm{a}_{1}, 0\right),\left(\mathrm{a}_{1}, 0\right)\right]$} & {$\left[\left(\mathrm{a}_{0}, 0\right),\left(\mathrm{a}_{1}, 0\right)\right]$} \\
\hline & $\mathrm{DM}_{3}$ & {$\left[\left(\mathrm{a}_{0}, 0\right),\left(\mathrm{a}_{1}, 0\right)\right]$} & {$\left[\left(\mathrm{a}_{1}, 0\right),\left(\mathrm{a}_{2}, 0\right)\right]$} & {$\left[\left(\mathrm{a}_{1}, 0\right),\left(\mathrm{a}_{1}, 0\right)\right]$} \\
\hline \multirow{2}{*}{$\left(A_{1}^{D_{1}}, A_{2}^{D_{3}}\right)$} & $D M_{1}$ & {$\left[\left(\mathrm{a}_{2}, 0\right),\left(\mathrm{a}_{2}, 0\right)\right]$} & {$\left[\left(\mathrm{a}_{2}, 0\right),\left(\mathrm{a}_{3}, 0\right)\right]$} & {$\left[\left(\mathrm{a}_{1}, 0\right),\left(\mathrm{a}_{2}, 0\right)\right]$} \\
\hline & $D M_{3}$ & {$\left[\left(\mathrm{a}_{1}, 0\right),\left(\mathrm{a}_{2}, 0\right)\right]$} & {$\left[\left(\mathrm{a}_{2}, 0\right),\left(\mathrm{a}_{2}, 0\right)\right]$} & {$\left[\left(\mathrm{a}_{1}, 0\right),\left(\mathrm{a}_{2}, 0\right)\right]$} \\
\hline \multirow{2}{*}{$\left(A_{2}^{D_{1}}, A_{1}^{D_{2}}\right)$} & $D M_{1}$ & {$\left[\left(\mathrm{a}_{3}, 0\right),\left(\mathrm{a}_{3}, 0\right)\right]$} & {$\left[\left(\mathrm{a}_{2}, 0\right),\left(\mathrm{a}_{3}, 0\right)\right]$} & {$\left[\left(\mathrm{a}_{2}, 0\right),\left(\mathrm{a}_{2}, 0\right)\right]$} \\
\hline & $D M_{2}$ & {$\left[\left(b_{3}, 0\right),\left(b_{4}, 0\right)\right]$} & {$\left[\left(\mathrm{b}_{4}, 0\right),\left(\mathrm{b}_{4}, 0\right)\right]$} & {$\left[\left(b_{3}, 0\right),\left(b_{3}, 0\right)\right]$} \\
\hline \multirow{2}{*}{$\left(A_{2}^{D_{1}}, A_{2}^{D_{2}}\right)$} & $D M_{1}$ & {$\left[\left(\mathrm{a}_{3}, 0\right),\left(\mathrm{a}_{4}, 0\right)\right]$} & {$\left[\left(\mathrm{a}_{3}, 0\right),\left(\mathrm{a}_{3}, 0\right)\right]$} & {$\left[\left(\mathrm{a}_{3}, 0\right),\left(\mathrm{a}_{4}, 0\right)\right]$} \\
\hline & $D M_{2}$ & {$\left[\left(b_{3}, 0\right),\left(b_{4}, 0\right)\right]$} & {$\left[\left(b_{5}, 0\right),\left(b_{5}, 0\right)\right]$} & {$\left[\left(b_{4}, 0\right),\left(b_{4}, 0\right)\right]$} \\
\hline \multirow[t]{2}{*}{$\left(A_{2}^{D_{1}}, A_{1}^{D_{3}}\right)$} & $D M_{1}$ & {$\left[\left(\mathrm{a}_{2}, 0\right),\left(\mathrm{a}_{3}, 0\right)\right]$} & {$\left[\left(\mathrm{a}_{2}, 0\right),\left(\mathrm{a}_{2}, 0\right)\right]$} & {$\left[\left(\mathrm{a}_{2}, 0\right),\left(\mathrm{a}_{2}, 0\right)\right]$} \\
\hline & $D M_{3}$ & {$\left[\left(\mathrm{a}_{3}, 0\right),\left(\mathrm{a}_{3}, 0\right)\right]$} & {$\left[\left(\mathrm{a}_{2}, 0\right),\left(\mathrm{a}_{2}, 0\right)\right]$} & {$\left[\left(\mathrm{a}_{1}, 0\right),\left(\mathrm{a}_{2}, 0\right)\right]$} \\
\hline \multirow[t]{2}{*}{$\left(A_{2}^{D_{1}}, A_{2}^{D_{3}}\right)$} & $D M_{1}$ & {$\left[\left(\mathrm{a}_{3}, 0\right),\left(\mathrm{a}_{4}, 0\right)\right]$} & {$\left[\left(\mathrm{a}_{2}, 0\right),\left(\mathrm{a}_{3}, 0\right)\right]$} & {$\left[\left(\mathrm{a}_{2}, 0\right),\left(\mathrm{a}_{3}, 0\right)\right]$} \\
\hline & $\mathrm{DM}_{3}$ & {$\left[\left(\mathrm{a}_{3}, 0\right),\left(\mathrm{a}_{3}, 0\right)\right]$} & {$\left[\left(\mathrm{a}_{3}, 0\right),\left(\mathrm{a}_{3}, 0\right)\right]$} & {$\left[\left(\mathrm{a}_{2}, 0\right),\left(\mathrm{a}_{2}, 0\right)\right]$} \\
\hline \multirow{2}{*}{$\left(A_{1}^{D_{2}}, A_{1}^{D_{3}}\right)$} & $D M_{2}$ & {$\left[\left(\mathrm{~b}_{4}, 0\right),\left(\mathrm{b}_{4}, 0\right)\right]$} & {$\left[\left(b_{3}, 0\right),\left(b_{5}, 0\right)\right]$} & {$\left[\left(b_{1}, 0\right),\left(b_{3}, 0\right)\right]$} \\
\hline & $D M_{3}$ & {$\left[\left(\mathrm{a}_{3}, 0\right),\left(\mathrm{a}_{4}, 0\right)\right]$} & {$\left[\left(\mathrm{a}_{3}, 0\right),\left(\mathrm{a}_{3}, 0\right)\right]$} & {$\left[\left(a_{1}, 0\right),\left(a_{1}, 0\right)\right]$} \\
\hline \multirow[t]{2}{*}{$\left(A_{1}^{D_{2}}, A_{2}^{D_{3}}\right)$} & $D M_{2}$ & {$\left[\left(b_{3}, 0\right),\left(b_{4}, 0\right)\right]$} & {$\left[\left(\mathrm{b}_{3}, 0\right),\left(\mathrm{b}_{4}, 0\right)\right]$} & {$\left[\left(b_{2}, 0\right),\left(b_{3}, 0\right)\right]$} \\
\hline & $D M_{3}$ & {$\left[\left(\mathrm{a}_{3}, 0\right),\left(\mathrm{a}_{3}, 0\right)\right]$} & {$\left[\left(\mathrm{a}_{3}, 0\right),\left(\mathrm{a}_{3}, 0\right)\right]$} & {$\left[\left(\mathrm{a}_{2}, 0\right),\left(\mathrm{a}_{3}, 0\right)\right]$} \\
\hline \multirow{2}{*}{$\left(A_{2}^{D_{2}}, A_{1}^{D_{3}}\right)$} & $D M_{2}$ & {$\left[\left(b_{3}, 0\right),\left(b_{3}, 0\right)\right]$} & {$\left[\left(\mathrm{b}_{3}, 0\right),\left(\mathrm{b}_{4}, 0\right)\right]$} & {$\left[\left(b_{3}, 0\right),\left(b_{3}, 0\right)\right]$} \\
\hline & $D M_{3}$ & {$\left[\left(\mathrm{a}_{2}, 0\right),\left(\mathrm{a}_{4}, 0\right)\right]$} & {$\left[\left(\mathrm{a}_{2}, 0\right),\left(\mathrm{a}_{3}, 0\right)\right]$} & {$\left[\left(\mathrm{a}_{2}, 0\right),\left(\mathrm{a}_{4}, 0\right)\right]$} \\
\hline \multirow{2}{*}{$\left(A_{2}^{D_{2}}, A_{2}^{D_{3}}\right)$} & $D M_{2}$ & {$\left[\left(b_{2}, 0\right),\left(b_{4}, 0\right)\right]$} & {$\left[\left(b_{3}, 0\right),\left(b_{3}, 0\right)\right]$} & {$\left[\left(b_{3}, 0\right),\left(b_{4}, 0\right)\right]$} \\
\hline & $D M_{3}$ & {$\left[\left(\mathrm{a}_{2}, 0\right),\left(\mathrm{a}_{3}, 0\right)\right]$} & {$\left[\left(\mathrm{a}_{2}, 0\right),\left(\mathrm{a}_{3}, 0\right)\right]$} & {$\left[\left(\mathrm{a}_{3}, 0\right),\left(\mathrm{a}_{4}, 0\right)\right]$} \\
\hline
\end{tabular}


Table A2 ITLBO vectors and ITLOW vectors regarding collaborative criteria

\begin{tabular}{llllll}
\hline Decision maker & $\begin{array}{l}\text { Most/least important } \\
\text { individual criterion }\end{array}$ & & \multicolumn{4}{l}{ ITLBO/ITLOW vector } \\
\cline { 3 - 6 } & Most important: $C C_{3}$ & $A_{B}^{1}$ & {$\left[\left(\mathrm{c}_{2}, 0\right),\left(\mathrm{c}_{3}, 0\right)\right]$} & {$\left[\left(\mathrm{c}_{2}, 0\right),\left(\mathrm{c}_{4}, 0\right)\right]$} & {$\left[\left(\mathrm{c}_{0}, 0\right),\left(\mathrm{c}_{0}, 0\right)\right]$} \\
\hline$D M_{1}$ & Least important: $C C_{2}$ & $A_{W}^{1}$ & {$\left[\left(\mathrm{c}_{1}, 0\right),\left(\mathrm{c}_{2}, 0\right)\right]$} & {$\left[\left(\mathrm{c}_{0}, 0\right),\left(\mathrm{c}_{0}, 0\right)\right]$} & {$\left[\left(\mathrm{c}_{2}, 0\right),\left(\mathrm{c}_{3}, 0\right)\right]$} \\
& Most important: $C C_{1}$ & $A_{B}^{2}$ & {$\left[\left(\mathrm{~d}_{0}, 0\right),\left(\mathrm{d}_{0}, 0\right)\right]$} & {$\left[\left(\mathrm{d}_{3}, 0\right),\left(\mathrm{d}_{4}, 0\right)\right]$} & {$\left[\left(\mathrm{d}_{1}, 0\right),\left(\mathrm{d}_{2}, 0\right)\right]$} \\
$D M_{2}$ & Least important: $C C_{3}$ & $A_{W}^{2}$ & {$\left[\left(\mathrm{~d}_{3}, 0\right),\left(\mathrm{d}_{3}, 0\right)\right]$} & {$\left[\left(\mathrm{d}_{1}, 0\right),\left(\mathrm{d}_{1}, 0\right)\right]$} & {$\left[\left(\mathrm{d}_{0}, 0\right),\left(\mathrm{d}_{0}, 0\right)\right]$} \\
& Most important: $C C_{1}$ & $A_{B}^{3}$ & {$\left[\left(\mathrm{c}_{0}, 0\right),\left(\mathrm{c}_{0}, 0\right)\right]$} & {$\left[\left(\mathrm{c}_{2}, 0\right),\left(\mathrm{c}_{3}, 0\right)\right]$} & {$\left[\left(\mathrm{c}_{1}, 0\right),\left(\mathrm{c}_{1}, 0\right)\right]$} \\
$D M_{3}$ & Least important: $C C_{2}$ & $A_{W}^{3}$ & {$\left[\left(\mathrm{c}_{2}, 0\right),\left(\mathrm{c}_{2}, 0\right)\right]$} & {$\left[\left(\mathrm{c}_{0}, 0\right),\left(\mathrm{c}_{0}, 0\right)\right]$} & {$\left[\left(\mathrm{c}_{1}, 0\right),\left(\mathrm{c}_{2}, 0\right)\right]$} \\
& & & & &
\end{tabular}

Acknowledgements This work is supported by the National Key R\&D Program of China [Grant Number 2016YFC0801500]; the Youth Project of Party School of the Central Committee of C.P.C (National Academy of Governance) [Project Number 2021QN045]; the Fundamental Research Funds for the Central Universities [Grant Number WK2320000040]; and the Research Grants Council of the Hong Kong Special Administrative Region, China [Project Number 9042476 CityU 11201817]. Dr. Q.S Wang is supported by Youth Innovation Promotion Association CAS [Grant Numbers 2013286].

Author contributions Conceptualization: KQ, HC; Methodology: KQ; Formal analysis and investigation: QD, YD; Writing —original draft preparation: KQ; Writing_-review and editing: QW, HC; Funding acquisition: QW, JS, KML; Validation: YD; Supervision: JS.

Availability of data and material Not applicable.

Code availability Not applicable.

\section{Declarations}

Conflict of interest The authors declare that they have no conflict of interest.

Ethical standards Not applicable.

\section{References}

1. Abdellaoui M, Bleichrodt H, Paraschiv C (2007) Loss aversion under prospect theory: a parameter-free measurement. Manage Sci 53:1659-1674. https://doi.org/10.1287/mnsc.1070.0711

2. Ashraf S, Abdullah S (2020) Emergency decision support modeling for COVID-19 based on spherical fuzzy information. Int J Intell Syst 35:1601-1645. https://doi.org/10.1002/int.22262

3. Camerer C (1998) Bounded rationality in individual decision making. Exper Econ 1:163-183. https://doi.org/10.1023/A:10099 44326196

4. Chen L, Li Z, Deng X (2020) Emergency alternative evaluation under group decision makers: a new method based on entropy weight and DEMATEL. Int J Syst Sci 51:570-583. https://doi. org/10.1080/00207721.2020.1723731

5. Chen Z, Liu X, Chin K, Pedrycz W, Tsui KL, Skibniewski MJ (2020) Online-review analysis based large-scale group decisionmaking for determining passenger demands and evaluating passenger satisfaction: case study of high-speed rail system in China. Inform Fusion. https://doi.org/10.1016/j.inffus.2020.11.010

6. Chen S, Yu D, Zheng X, Chen A (2014) Study on synergistic emergency response to major events. China Safe Sci J 24:156-162
7. Ding X, Liu H (2019) A new approach for emergency decisionmaking based on zero-sum game with Pythagorean fuzzy uncertain linguistic variables. Int J Intell Syst 34:1667-1684. https:// doi.org/10.1002/int.22113

8. Ding X, Liu H (2019) An extended prospect theory-VIKOR approach for emergency decision making with 2-dimension uncertain linguistic information. Soft Comput 23:12139-12150. https:// doi.org/10.1007/s00500-019-04092-2

9. Ding Q, Wang Y, Goh M (2021) An extended TODIM approach for group emergency decision making based on bidirectional projection with hesitant triangular fuzzy sets. Comput Ind Eng 151:106959. https://doi.org/10.1016/j.cie.2020.106959

10. Ding Q, Wang Y, Goh M (2021) TODIM dynamic emergency decision-making method based on hybrid weighted distance under probabilistic hesitant fuzzy information. Int J Fuzzy Syst. https:// doi.org/10.1007/s40815-020-00978-8

11. Ding X, Zhu L, Lu M, Wang Q, Feng Y (2020) A novel linguistic Z-number QUALIFLEX method and its application to large group emergency decision making. Sci Programm 2020:1-12. https:// doi.org/10.1155/2020/1631869

12. Forozesh N, Karimi B, Mousavi SM (2020) Assessing suppliers in green supply chain based on a group compromise solution approach with interval-valued 2-tuple linguistic information. J Qual Eng Prod Optim. https://doi.org/10.22070/JQEPO.2020.5174.1129

13. Gao J, Xu Z, Ren P, Liao H (2019) An emergency decision making method based on the multiplicative consistency of probabilistic linguistic preference relations. Int J Mach Learn Cybern 10:16131629. https://doi.org/10.1007/s13042-018-0839-0

14. Gomes L, Lima M (1992) TODIM: Basics and application to multicriteria ranking of projects with environmental impacts. Found Comput Decis Sci 16:113-127

15. Gul M, Ak MF (2020) Assessment of occupational risks from human health and environmental perspectives: a new integrated approach and its application using fuzzy BWM and fuzzy MAIRCA. Stoch Env Res Risk A. https://doi.org/10.1007/ s00477-020-01816-x

16. Hafezalkotob A, Hafezalkotob A, Liao H, Herrera F (2019) Interval MULTIMOORA method integrating interval Borda rule and interval best-worst-method-based weighting model: Case study on hybrid vehicle engine selection. IEEE Trans Cybernet 50:1157-1169. https://doi.org/10.1109/TCYB.2018.2889730

17. Herrera F, Martínez L (2000) A 2-tuple fuzzy linguistic representation model for computing with words. IEEE Trans Fuzzy Syst 8:746-752. https://doi.org/10.1109/91.890332

18. Ju Y, Wang A (2012) Emergency alternative evaluation under group decision makers: a method of incorporating DS/AHP with extended TOPSIS. Expert Syst Appl 39:1315-1323. https://doi. org/10.1016/j.eswa.2011.08.012

19. Kahneman D, Tversky A (2013) Prospect theory: an analysis of decision under risk. In: Handbook of the fundamentals of financial decision making: Part I. World Scientific, pp 99-127. https://doi. org/10.1142/9789814417358_0006 
20. Keshavarz Ghorabaee M, Zavadskas EK, Turskis Z, Antucheviciene $\mathrm{J}$ (2016) A new combinative distance-based assessment (CODAS) method for multi-criteria decision-making. Econ Comput Econ Cybern Stud Res 50:25-44

21. Li G, Li Y, Chen C, He J, Hou T, Chen J (2020) Advanced FMEA method based on interval 2-tuple linguistic variables and TOPSIS. Qual Eng 32:653-662. https://doi.org/10.1080/08982112.2019. 1677913

22. Li P, Wei C (2019) An emergency decision-making method based on DS evidence theory for probabilistic linguistic term sets. Int J Disast Risk Re 37:101178. https://doi.org/10.1016/j.ijdrr.2019. 101178

23. Li H, You J, Liu H, Tian G (2018) Acquiring and sharing tacit knowledge based on interval 2-tuple linguistic assessments and extended fuzzy Petri nets. Int J Uncertain Fuzz Knowl Based Syst 26:43-65. https://doi.org/10.1142/S0218488518500034

24. Liang Y, Liu J, Qin J, Tu Y (2019) An improved multi-granularity interval 2-tuple TODIM approach and its application to green supplier selection. Int J Fuzzy Syst 21:129-144. https://doi.org/ 10.1007/s40815-018-0546-8

25. Liang X, Teng F, Sun Y (2020) Multiple group decision making for selecting emergency alternatives: a novel method based on the LDWPA operator and LD-MABAC. Int J Env Res Public Health 17:2945. https://doi.org/10.3390/ijerph17082945

26. Liang Y, Tu Y, Ju Y, Shen W (2019) A multi-granularity proportional hesitant fuzzy linguistic TODIM method and its application to emergency decision making. Int J Disast Risk Re 36:101081. https://doi.org/10.1016/j.ijdrr.2019.101081

27. Liao H, Mi X, Yu Q, Luo L (2019) Hospital performance evaluation by a hesitant fuzzy linguistic best worst method with inconsistency repairing. J Clean Prod 232:657-671. https://doi.org/10. 1016/j.jclepro.2019.05.308

28. Liao H, Wen Z, Liu L (2019) Integrating BWM and ARAS under hesitant linguistic environment for digital supply chain finance supplier section. Technol Econ Dev Econ 25:1188-1212. https:// doi.org/10.3846/tede.2019.10716

29. Liu B, Fu M, Zhang S, Xue B, Zhou Q, Zhang S (2018) An interval-valued 2-tuple linguistic group decision-making model based on the Choquet integral operator. Int J Syst Sci 49:407-424. https://doi.org/10.1080/00207721.2017.1407007

30. Liu H, Lin Q, Wu J (2014) Dependent interval 2-tuple linguistic aggregation operators and their application to multiple attribute group decision making. Int J Uncertain Fuzz 22:717-735. https:// doi.org/10.1142/S0218488514500366

31. Liu P, Rong L, Teng F (2019) The evaluation of ecosystem health based on hybrid TODIM method for Chinese case. Technol Econ Dev Econ 25:542-570. https://doi.org/10.3846/tede.2019.8021

32. Liu P, Shen M, Teng F, Zhu B, Rong L, Geng Y (2021) Double hierarchy hesitant fuzzy linguistic entropy-based TODIM approach using evidential theory. Inform Sci 547:223-243. https:// doi.org/10.1016/j.ins.2020.07.062

33. Liu P, Teng F (2015) An extended TODIM method for multiple attribute group decision making based on intuitionistic uncertain linguistic variables. J Intell Fuzzy Syst 29:701-711. https://doi. org/10.3233/IFS-141441

34. Liu P, Teng F (2016) An extended TODIM method for multiple attribute group decision-making based on 2-dimension uncertain linguistic variable. Complexity 21:20-30. https://doi.org/10.1002/ cplx.21625

35. Liu P, Teng F (2019) Probabilistic linguistic TODIM method for selecting products through online product reviews. Inform Sci 485:441-455. https://doi.org/10.1016/j.ins.2019.02.022

36. Liu Y, Wang Y, Xu M, Xu G (2019) Emergency alternative evaluation using extended trapezoidal intuitionistic fuzzy thermodynamic approach with prospect theory. Int J Fuzzy Syst 21:18011817. https://doi.org/10.1007/s40815-019-00682-2
37. Liu H, You J, You X (2014) Evaluating the risk of healthcare failure modes using interval 2-tuple hybrid weighted distance measure. Comput Ind Eng 78:249-258. https://doi.org/10.1016/j.cie. 2014.07.018

38. Liu A, Zhu Q, Liu H, Lu H, Tsai S-B (2018) A novel approach based on kano model, interval 2-tuple linguistic representation model, and prospect theory for apperceiving key customer requirements. Math Prob Eng. https://doi.org/10.1155/2018/8192819

39. Liu P, Zhu B, Wang P (2021) A weighting model based on bestworst method and its application for environmental performance evaluation. Appl Soft Comput 103:107168. https://doi.org/10. 1016/j.asoc.2021.107168

40. Liu P, You X (2019) Improved TODIM method based on linguistic neutrosophic numbers for multicriteria group decision-making. Int J Comput Intell Syst 12:544-556. https://doi.org/10.2991/ijcis.d. 190412.001

41. Lo H, Liou J, Huang C, Chuang Y (2019) A novel failure mode and effect analysis model for machine tool risk analysis. Reliab Eng Syst Safe 183:173-183. https://doi.org/10.1016/j.ress.2018. 11.018

42. Maghsoodi AI, Rasoulipanah H, López LM, Liao H, Zavadskas EK (2020) Integrating interval-valued multi-granular 2-tuple linguistic BWM-CODAS approach with target-based attributes: Site selection for a construction project. Comput Ind Eng 139:106147. https://doi.org/10.1016/j.cie.2019.106147

43. Mi X, Tang M, Liao H, Shen W, Lev B (2019) The state-of-the-art survey on integrations and applications of the best worst method in decision making: Why, what, what for and what's next? Omega 87:205-225. https://doi.org/10.1016/j.omega.2019.01.009

44. Norouzi A, Namin HG (2019) A hybrid fuzzy TOPSIS-best worst method for risk prioritization in megaprojects. Civ Eng J 5:12571272. https://doi.org/10.28991/cej-2019-03091330

45. Pegoraro F, Santos EAP, Loures EdFR, Laus FW (2020) A hybrid model to support decision making in emergency department management. Knowl-Based Syst 203:106148. https://doi.org/10. 1016/j.knosys.2020.106148

46. Peng X, Garg H (2018) Algorithms for interval-valued fuzzy soft sets in emergency decision making based on WDBA and CODAS with new information measure. Comput Ind Eng 119:439-452. https://doi.org/10.1016/j.cie.2018.04.001

47. Peng X, Yuan H, Yang Y (2017) Pythagorean fuzzy information measures and their applications. Int J Intell Syst 32:991-1029. https://doi.org/10.1002/int.21880

48. Qi K, Wang Q, Duan Q, Gong L, Sun J, Liew K, Jiang L (2018) A multi criteria comprehensive evaluation approach for emergency response capacity with interval 2-tuple linguistic information. Appl Soft Comput 72:419-441. https://doi.org/10.1016/j.asoc. 2018.07.043

49. Qin J, Liu X, Pedrycz W (2017) An extended TODIM multi-criteria group decision making method for green supplier selection in interval type-2 fuzzy environment. Eur J Oper Res 258:626-638. https://doi.org/10.1016/j.ejor.2016.09.059

50. Rezaei J (2015) Best-worst multi-criteria decision-making method. Omega 53:49-57. https://doi.org/10.1016/j.omega.2014. 11.009

51. Rezaei J (2016) Best-worst multi-criteria decision-making method: Some properties and a linear model. Omega 64:126-130. https://doi.org/10.1016/j.omega.2015.12.001

52. Rong Y, Liu Y, Pei Z (2021) A novel multiple attribute decision-making approach for evaluation of emergency management schemes under picture fuzzy environment. Int J Mach Learn Cybern. https://doi.org/10.1007/s13042-021-01280-1

53. Singh A, Gupta A, Mehra A (2017) Energy planning problems with interval-valued 2-tuple linguistic information. Oper Res-Ger 17:821-848. https://doi.org/10.1007/s12351-016-0245-x 
54. Sugihara K, Ishii H, Tanaka H (2004) Interval priorities in AHP by interval regression analysis. Eur J Oper Res 158:745-754. https://doi.org/10.1016/S0377-2217(03)00418-1

55. Sun B, Ma W (2016) An approach to evaluation of emergency plans for unconventional emergency events based on soft fuzzy rough set. Kyb. https://doi.org/10.1108/K-03-2014-0055

56. Tai W, Chen C (2009) A new evaluation model for intellectual capital based on computing with linguistic variable. Expert Syst Appl 36:3483-3488. https://doi.org/10.1016/j.eswa.2008.02.017

57. Teng F, Liu P (2021) A large group decision-making method based on a generalized Shapley probabilistic linguistic Choquet average operator and the TODIM method. Comput Ind Eng 151:106971. https://doi.org/10.1016/j.cie.2020.106971

58. Tversky A, Kahneman D (1992) Advances in prospect theory: cumulative representation of uncertainty. J Risk Uncertain 5:297323. https://doi.org/10.1007/BF00122574

59. Wan S, Xu G, Dong J (2017) Supplier selection using ANP and ELECTRE II in interval 2-tuple linguistic environment. Inform Sci 385:19-38. https://doi.org/10.1016/j.ins.2016.12.032

60. Wang X, Cai J (2017) A group decision-making model based on distance-based VIKOR with incomplete heterogeneous information and its application to emergency supplier selection. Kyb. https://doi.org/10.1108/K-06-2016-0132

61. Wang Y, Liang Y, Sun H (2020) A regret theory-based decisionmaking method for urban rail transit in emergency response of rainstorm disaster. J Adv Transport. https://doi.org/10.1155/2020/ 3235429

62. Wang W, Day W (2020) Applying AHP to evaluate the decision priority of typhoon disaster preparedness and emergency response. Disaster Sci 5:27-52

63. Wu Z, Zhang S, Liu X, Wu J (2019) Best-worst multi-attribute decision making method based on new possibility degree with probabilistic linguistic information. IEEE Access 7:133900133913. https://doi.org/10.1109/ACCESS.2019.2941821

64. Wu Q, Zhou L, Chen Y, Chen H (2019) An integrated approach to green supplier selection based on the interval type-2 fuzzy best-worst and extended VIKOR methods. Inform Sci 502:394417. https://doi.org/10.1016/j.ins.2019.06.049

65. Xia D, Li C, Xin J, Zhu Y (2021) A method for emergency response alternative decision-making under uncertainty. J Control Decis. https://doi.org/10.1080/23307706.2020.1867011

66. Xu X, Du Z, Chen X (2015) Consensus model for multi-criteria large-group emergency decision making considering non-cooperative behaviors and minority opinions. Decis Support Syst 79:150-160. https://doi.org/10.1016/j.dss.2015.08.009

67. Yazdi M, Nedjati A, Zarei E, Abbassi R (2020) A reliable risk analysis approach using an extension of best-worst method based on democratic-autocratic decision-making style. J Clean Prod 256:120418. https://doi.org/10.1016/j.jclepro.2020.120418

68. Zadeh LA (1975) The concept of a linguistic variable and its application to approximate reasoning-I. Inform Sci 8:199-249. https://doi.org/10.1016/0020-0255(75)90036-5

69. Zhang H (2012) The multiattribute group decision making method based on aggregation operators with interval-valued 2-tuple linguistic information. Math Comput Model 56:27-35. https://doi. org/10.1016/j.mcm.2012.01.001

70. Zhang Z, Wang L, Wang Y (2018) An emergency decision making method based on prospect theory for different emergency situations. Int J Disast Risk Sc 9:407-420. https://doi.org/10.1007/ s13753-018-0173-X

71. Zhang L, Wang Y, Zhao X (2018) A new emergency decision support methodology based on multi-source knowledge in 2-tuple linguistic model. Knowl-Based Syst 144:77-87. https://doi.org/10. 1016/j.knosys.2017.12.026

72. Zhou L, Wu X, Xu Z, Fujita H (2018) Emergency decision making for natural disasters: an overview. Int J Disast Risk Re 27:567576. https://doi.org/10.1016/j.ijdrr.2017.09.037

Publisher's Note Springer Nature remains neutral with regard to jurisdictional claims in published maps and institutional affiliations. 